\title{
Implications of testicular ACE2 and the renin-angiotensin system for SARS-CoV-2 on testis function
}

\section{R. Clayton Edenfield (D) and Charles A. Easley IV (D)}

Abstract | Although many studies have focused on SARS-CoV-2 infection in the lungs, comparatively little is known about the potential effects of the virus on male fertility. SARS-CoV-2 infection of target cells requires the presence of furin, angiotensin-converting enzyme 2 (ACE2) receptors, and transmembrane protease serine 2 (TMPRSS2). Thus, cells in the body that express these proteins might be highly susceptible to viral entry and downstream effects. Currently, reports regarding the expression of the viral entry proteins in the testes are conflicting; however, other members of the SARS-CoV family of viruses - such as SARS-CoV - have been suspected to cause testicular dysfunction and/or orchitis. SARS-CoV-2, which displays many similarities to SARS-CoV, could potentially cause similar adverse effects. Commonalities between SARS family members, taken in combination with sparse reports of testicular discomfort and altered hormone levels in patients with SARS-CoV-2, might indicate possible testicular dysfunction. Thus, SARS-CoV-2 infection has the potential for effects on testis somatic and germline cells and experimental approaches might be required to help identify potential short-term and long-term effects of SARS-CoV-2 on male fertility.

In late December 2019, SARS-CoV-2 was discovered in Wuhan, China. The resulting disease was termed coronavirus disease 2019 (COVID-19). The virus causes similar clinical characteristics to viral pneumonia and went on to kill $>70,000$ people in the first 50 days of the epidemic ${ }^{1}$. The novel coronavirus quickly spread: at the time of writing, 250 million people have been infected, and 5 million people have died worldwide $^{2}$. Many studies have focused on the effects of SARS-CoV-2 infection in the lungs, and comparatively little is known about the effects of COVID-19 on male fertility.

This Perspectives article will cover the potential risks of infection on somatic and germline cells of the testis, as well as considering other male organs that are susceptible to SARS-CoV-2 infection and that could affect semen parameters as well as considering the models and methods that could be used to examine the effects of SARS-CoV-2 on male fertility.

\section{Characteristics of SARS-COV-2 and COVID-19 infection}

Major risk factors for SARS-COV-2 infection include being male and aged over 65 years ${ }^{3}$. Comorbidities such as hypertension, obesity, hypercholesterolaemia, diabetes, cardiovascular disease and respiratory diseases seem to significantly worsen the prognosis of COVID-19 ( REFS $^{4-7}$ ). COVID-19 is primarily characterized by fever, cough, fatigue and myalgia ${ }^{8}$, which follow a standard course of four main stages: first, upper respiratory tract infection, followed by onset of dyspnoea and pneumonia, then, third, cytokine storm and hyperinflammatory state and, finally, death or recovery ${ }^{9}$. However, a range of symptoms have been reported across multiple organ systems. Gastrointestinal symptoms are reported in $40 \%$ of patients and include anorexia, nausea, vomiting and diarrhoea $^{10}$. Neurological manifestations affect $36 \%$ of patients and $45 \%$ of those with severe infection; these include symptoms of dizziness, headache, impaired consciousness, acute cerebrovascular disease, ataxia, seizures, olfactory disorders and nerve pain $^{11,12}$. The incidence of cardiovascular manifestations is high and diverse; early studies indicate that 7-20\% of COVID- 19 patients experience acute myocardial injury, $24 \%$ had heart failure and $17 \%$ displayed cardiac arrhythmia ${ }^{13}$, which is probably due to a systemic inflammatory response and immune system inhibition during disease progression $^{14}$.

This wide array of symptoms indicates that SARS-CoV-2 is able to access several organ systems through indirect and direct mechanisms, possibly gaining entry to multiple organ systems that express viral entry proteins. The broad tropism of SARS-CoV-2 is also indicated by the detection of the virus in the pharynx, trachea, lungs, blood, heart, vessels, intestines, liver, male genitals, brain and kidneys ${ }^{15,16}$. Furthermore, many COVID-19 symptoms persist after acute infection (long COVID) suggesting possible tissue damage $^{17-19}$.

Coronaviruses are large, enveloped, positive single-stranded RNA viruses ranging from 27 to $32 \mathrm{~kb}$ and are known to infect humans, other mammals and birds, causing multi-organ system disease. They are split into four types: alpha-, beta-, deltaand gammacoronaviruses, according to their antigenic activity ${ }^{20}$. Seven coronaviruses have been shown to cause human disease characterized by respiratory infection; two alphacoronaviruses - H-CoV-NL63 and $\mathrm{H}-\mathrm{CoV}-229 \mathrm{E}-$ and two betacoronaviruses - H-CoV-OC43 and H-CoV-HKU1 cause mild respiratory infection ${ }^{21}$, whereas three betacoronaviruses - SARS-CoV, MERS-CoV and SARS-CoV-2 - are highly pathogenic ${ }^{22}$. SARS-CoV-2 is genomically similar to SARS-CoV, with which it shares $79.5 \%$ of its sequence ${ }^{23}$, and to Middle East respiratory syndrome coronavirus (MERS-CoV), sharing 50\% genomic homology ${ }^{24}$. However, SARS-CoV-2 has high transmissibility and infectivity and a low mortality rate compared with both SARS-CoV and MERS-CoV ${ }^{25}$. Two studies have shown that the basic reproduction number of SARS-CoV-2 falls between 2 and $3\left(\mathrm{REFS}^{26,27}\right)$, whereas the reproduction number of SARS-CoV is between 2.2 and 
3.6 $\left(\mathrm{REF}^{28}{ }^{28}\right.$ ) and that of MERS-CoV is 2.0-6.7 $\left(\mathrm{REF}^{29}\right)$, indicating the higher transmissibility of SARS-CoV-2 (REF. ${ }^{27}$ ).

All coronaviruses encode proteins for viral replication and nucleocapsid and envelope formation. The viral envelope is composed of three structural proteins: the matrix and envelope proteins, which are involved in virus assembly, and the spike surface glycoprotein, which mediates viral entry $^{30}$. These spike proteins form large protrusions on the surface, giving the appearance of a crown.

\section{Viral entry into cells}

SARS-CoV-2 has the typical coronavirus structure $^{22,31}$, sharing a high degree of spike homology with SARS-CoV 32,33 . The spike protein of SARS-CoV-2 mediates viral entry into host cells and is the determinant factor of viral infectivity, host range, tissue tropism and immune response induction ${ }^{34}$. The SARS-CoV-2 spike protein consists of the $\mathrm{S} 1$ subunit, a clover-shaped trimer, and S2 subunits, trimeric stalks linked to the S1 trimer $^{35,36}$. The receptor-binding domain (RBD) lies on the tip of the S1 head ${ }^{32}$ and is only loosely connected, enabling the infection of multiple host cells ${ }^{37}$ (FIG. 1). The RBDs of SARS-CoV, MERS-CoV and SARS-CoV-2 recognize exopeptidases on the host cell ${ }^{38}$. Angiotensin-converting enzyme 2 (ACE2) is the critical receptor for cellular entry of H-CoV-NL63, SARS-CoV and SARS-CoV-2 (REF. ${ }^{39}$ ), but not MERS-CoV $35,38,40,41$. The SARS-CoV RBD on the $\mathrm{S} 1$ unit binds to the outer surface of the host ACE2, away from its zinc-chelating enzymatic site ${ }^{42-44}$. Upon exopeptidase binding, entry into the cell depends on cellular proteases; transmembrane protease serine 2 (TMPRSS2) splits the spike protein enabling further penetration of SARS-CoV-2 (REFS ${ }^{45,46}$ ).

The entry mechanisms of SARS-CoV-2 have been directly demonstrated in a study showing that the virus uses ACE2 as a cellular entry receptor in multiple species, including humans, and does not use other typical coronavirus receptors such as amino peptidase $\mathrm{N}$ and dipeptidyl peptidase 4 (REFS ${ }^{22,47-49}$ ). ACE2 binding is facilitated by furin, a poly-substrate convertase ${ }^{5}$, which cleaves the SARS-CoV-2 polybasic cleavage site on the viral spike ${ }^{50}$ causing the RBD to swing out and become available for ACE2 binding. The ubiquitous expression of furin means it has great potential for viral infiltration, and it is commonly hijacked by viruses such as Ebola, herpes and retrovirus. Additionally, furin is transactivated by cytokine stimulation $^{51}$, possibly allowing increased infectivity during an immune response. SARS-CoV-2 is the only coronavirus to display furin cleavage ${ }^{52}$, which helps to explain its infectivity.

RNA viruses have a high mutation rate r $^{53}$, which results in changes to protein surface amino acids that can alter viral function and possibly lead to increased infectivity, transmissibility and mortality ${ }^{54}$. Mutations in the spike protein are of particular interest, as they can enhance viral entry and protein binding, for instance, the D614G mutation increases entrance efficiency through enhanced ACE2 binding affinity ${ }^{55}$. From September 2020 to June 2021, a total of 71 unique SARS-CoV-2 lineages were identified in England that contributed to SARS-CoV-2 infectivity ${ }^{56}$. Mutation sites have been identified, distributed across the spike protein sequence of SARS-CoV-2, with the maximum mutation density near the protease cleavage site. Additionally, the viral $\mathrm{RBD}$ is associated with 44 known mutation sites $^{57}$.

The importance of furin, ACE2 and TMPRSS2 in viral entry and infection suggests that environmental factors regulating these proteins could affect SARS-CoV-2 infection and severity. Specific comorbidities - such as hormone dysregulation $^{58-60}$, increased age ${ }^{61}$, obesity ${ }^{62}$, diabetes $^{63}$ and high blood pressure ${ }^{64}-$ can substantially increase SARS-CoV-2 risk by altering expression of ACE2, TMPRSS2 or furin ${ }^{65,66}$. Furthermore, other factors, such as alcohol intake, cholesterol levels ${ }^{67}$, smoking ${ }^{68}$ and hormone-altering chemicals $^{69}$, can also affect COVID-19 severity by potentially dysregulating and aggregating viral entry proteins. Furin is ubiquitous among all human cell types ${ }^{70}$; thus, infection is primarily driven by ACE2 and TMPRSS2 co-expression ${ }^{71}$. ACE2 and TMPRSS2 display a broad distribution in various human organs, being co-expressed in the lung, nose, gall bladder, small intestine, large intestine, oesophagus, brain, fallopian tube, testis, heart and kidney. However, SARS-CoV and SARS-CoV-2 have also been shown to enter cells through promiscuous proteases such as cathepsin $\mathrm{B} / \mathrm{L}^{72-74}$. Furthermore, as TMPRSS2 has been identified in extracellular vesicles, it might be able to reach tissues distant from where it is expressed, possibly contributing a

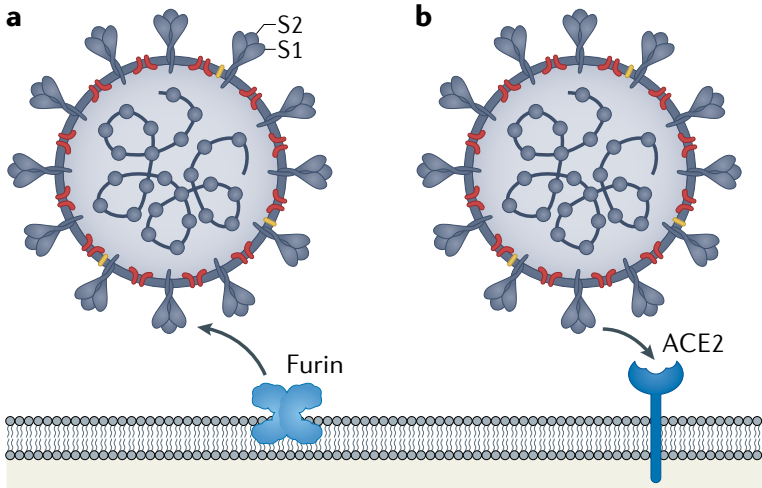

c

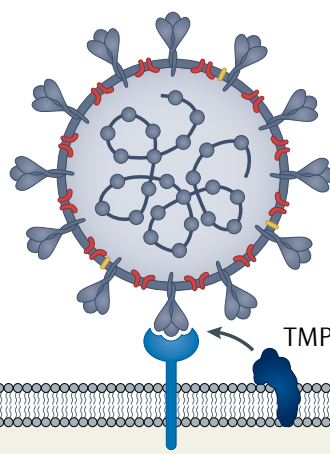

d

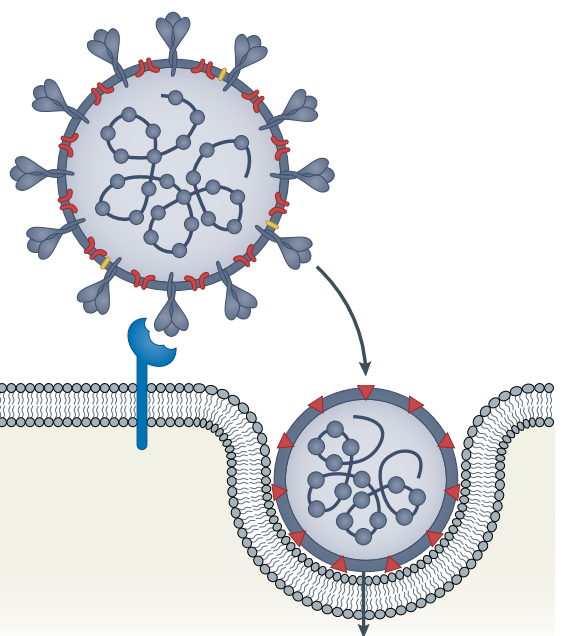

Fig. 1 | Mechanisms of SARS-CoV-2 cellular entry. a | The transmembrane convertase furin ${ }^{235}$ cleaves and activates the S1 subunit of the SARS-CoV-2 spike glycoprotein, opening the viral receptor-binding domain (RBD). b | When the RBD is in an open conformation, it can attach to angiotensin-converting enzyme 2 (ACE2) (48,236,237 c | Transmembrane protease serine 2 (TMPRSS2) is recruited to cleave the S1 subunit of the SARS-CoV-2 spike protein ${ }^{238}$, enabling entry. $\mathbf{d} \mid$ After ACE2 binding and protease cleavage, viral entry can occur. 


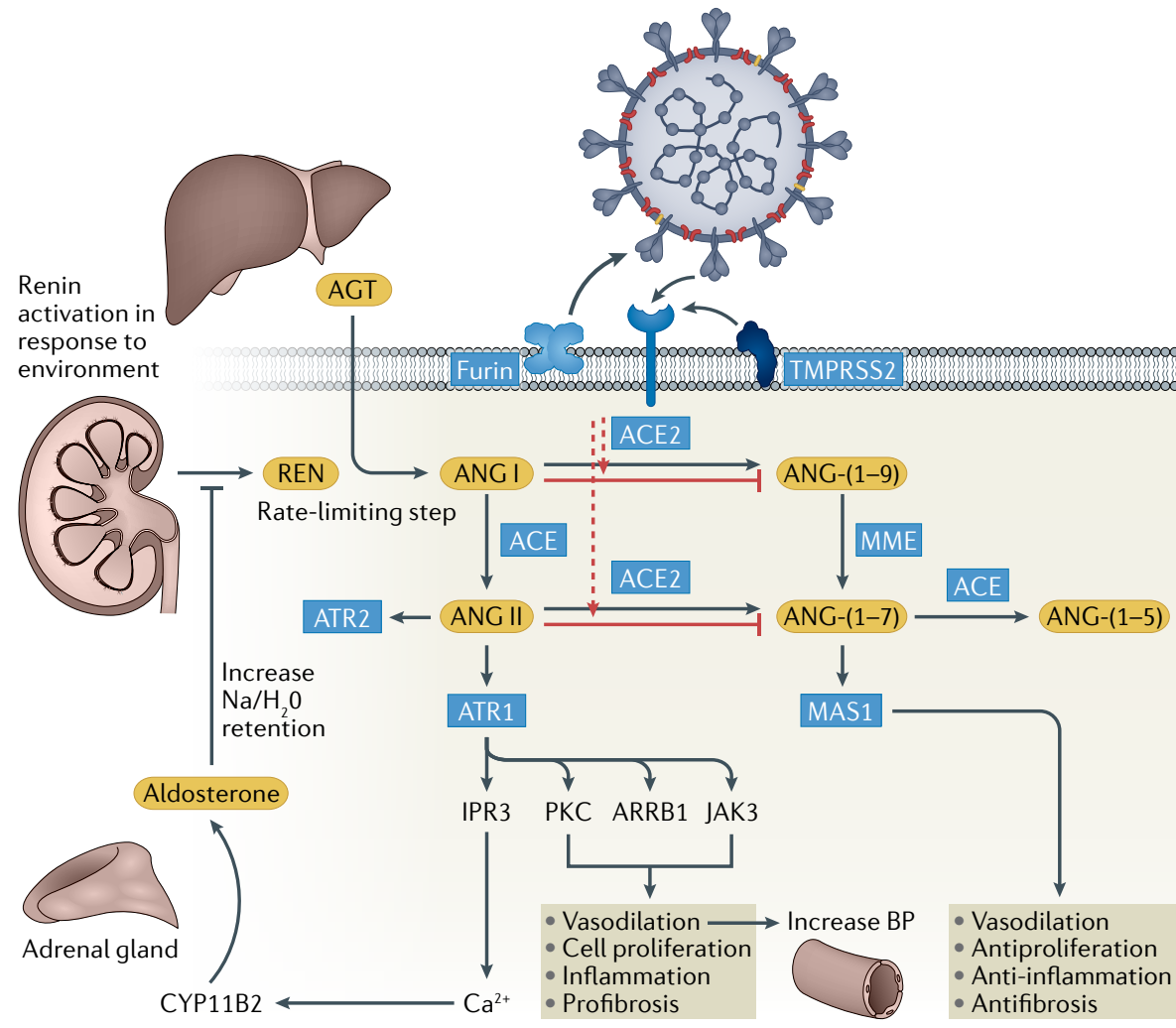

Fig. 2 | RAAS activation mechanisms. The renin-angiotensin-aldosterone system (RAAS) activates in response to several environmental factors, including low blood pressure (BP) and fluid volume. In response to the environmental factor, the kidneys produce renin, which is quickly cleaved by angiotensinogen, which is continuously produced by the liver, into angiotensin I (ANG I). Both angiotensinconverting enzyme 2 (ACE2) and ACE can cleave ANG I, but ACE has a much higher affinity for it than ACE2. ACE will convert ANG I into ANG II, where it has many downstream effects to counteract the environmental factor, and will eventually produce aldosterone to deactivate RAAS in a negative feedback mechanism. ACE2 converts ANG II into ANG-(1-7). ANG-(1-7) binds to mitochondrial assembly 1 (MAS1), which has various protective effects in response to those caused by ATR1. When RAAS is overstimulated, ACE2, the viral entry point of SARS-CoV-2, is upregulated, providing more entry points. SARS-CoV-2 interferes with the protective function of ACE2, worsening outcomes in patients with COVID-19. This effect is particularly important in those with low ACE2, in whom the ACE-ANG IANG II-ATR1 axis becomes overactive. ATR1, angiotensin receptor 1; TMPRSS2, transmembrane protease serine 2 .

to SARS-CoV-2 infection ${ }^{75}$. Although the necessity of TMPRSS2 for SARS-CoV-2 infection is still uncertain, ACE2 expression alongside a suitable protease clearly drives COVID-19 pathology.

\section{The importance of ACE2 and the RAAS}

ACE2 has a vital role in regulating the reninangiotensin-aldosterone system (RAAS) ${ }^{76}$ (FIG. 2). The RAAS is activated in response to low blood pressure, low fluid volume and specific agonists, such as salt loading ${ }^{77}$ and macrophage differentiation ${ }^{78}$, resulting in activation of angiotensin receptor 1 (ATR1) to cause vasoconstriction, cell proliferation, inflammation and fibrosis ${ }^{79}$. This process occurs via the angiotensin-converting enzyme-angiotensin I (ANG I)angiotensin II (ANG II)-ATR1 axis. ACE2 is activated to mitigate these effects ${ }^{80}$ through its effector protein angiotensin(1-7) (ANG-(1-7)) and major receptor mitochondrial assembly 1 (MAS1) ${ }^{81,82}$. The ACE2-ANG-(1-7)-MAS1 axis has a protective effect, causing vasodilation, anti-inflammation, antiproliferation and antifibrosis, which mitigate the effect of ATR1 (REF. ${ }^{82}$ ). Common COVID-19 comorbidities such as hypertension, diabetes and heat exhaustion are associated with RAAS overactivation or ACE2 deficiency ${ }^{83}$. During RAAS overactivation, ACE2 can be upregulated, providing additional entry points for SARS-CoV and SARS-CoV-2, which enter cells via ACE2 and inhibit its protective response in ACE2-expressing tissues $^{84}$. Furthermore, in patients with deficient ACE2 expression, infection could further dysregulate the ACE-ANG I-ANG II-ATR1 and ACE2-ANG-(1-7)-MAS1 axes $^{85}$. Several studies ${ }^{76,86,87}$ suggest that these viruses became highly lethal because they deregulate a lung-protective pathway. Decreasing ACE2 activity through SARS-CoV-2 binding increases the acute effects of angiotensin ${ }^{88}$, which are in line with many COVID-19 symptoms ${ }^{89}$.

The RAAS is activated more in men than in women, characterized by higher levels of $\mathrm{ACE}^{90}$. However, men display lower levels of ACE2 (REF. $\left.{ }^{91}\right)$. This discrepancy might account for the worse COVID-19 outcomes observed in men than in women. The substantial involvement of ACE2 and the RAAS in vascular inflammation and remodelling illustrate the sensitivity of the vascular system to changes in blood pressure and inflammation ${ }^{92,93}$. Organs such as the brain, kidneys and testes are at an increased risk of viral-mediated damage $^{94}$. In the brain, which displays similar immune-privilege, gene expression ${ }^{95}$ and decreased inflammatory response to foreign antigens to that seen in the testis ${ }^{96}$, RAAS overactivation through ACE2 inhibition causes cognitive impairment ${ }^{97,98}$. Alongside the neuro-invasive potential of SARS-CoV-2 (REFS ${ }^{99,100}$ ), ACE2 inhibition seems to be integral to understanding SARS-CoV-2-associated neuropathology.

The RAAS and male fertility. The RAAS might also be relevant to male fertility that RAAS functions in the testes is well established and various aspects of the RAAS, including renin, ACE, MAS and ANG II, are expressed in Leydig cells, germ cells, and sperm ${ }^{101-104}$. These components are also found in the epididymis, vesicular glands, prostate, seminal vesicles, vas deferens and seminal plasma ${ }^{105}$. Additionally, infertile men with impaired spermatogonia displayed lower levels of ACE2, ANG-(1-7) and MAS ${ }^{106}$. MAS is also found at the mRNA and protein level of matured sperm in the acrosomal and tail regions and incubation of MAS with asthenozoospermic sperm improves sperm mobility ${ }^{107}$. Furthermore, MAS-null rodents exhibit a reduction in testis weight and sperm production $^{103}$.

However, the functions of local tissue-specific RAAS might operate independently of the systemic RAAS ${ }^{108}$. Notably, the brain, heart and testis display a local RAAS and the testes express a testicular ACE isoform that might have important roles in male fertility ${ }^{109}$. The involvement of the RAAS in the testis means that SARS-CoV-2 infiltration and interference with testicular ACE2 could lead to infection, loss of protective effects during inflammatory 
states, and coagulation and inflammation, which can disrupt spermatogenesis and testicular function ${ }^{110,111}$. Clinical evidence of an aetiological role of the RAAS in male infertility is currently lacking; however, many SARS-CoV-2-associated symptoms and comorbidities can affect male fertility, such as fever, hypoxia, inflammation, immune-system inhibition, obesity and cholesterol dyshomeostasis ${ }^{112}$. These interactions further complicate the question of whether SARS-CoV-2 can directly affect the testis via the RAAS or whether effects might be indirect through various immune responses and pre-existing pathological conditions.

\section{Does SARS-CoV-2 affect testicular function?}

The human testis is a complex multicellular system with the primary function of producing spermatozoa and androgens, the inhibition of which by viral pathogens could have severe effects on testicular function ${ }^{113}$.

\section{Testicular cell types}

The testis comprises three major cell types: Leydig, Sertoli and germ cells. The interaction between these cells drives spermatogenesis. Sertoli and germ cells are the primary components of the seminiferous epithelium ${ }^{114}$. Spermatogonial stem cells (SSCs) are localized in the basal epithelium and are adjacent to the Sertoli cells, which produce various factors, such as glial-derived neurotrophic factor and CYP26B1 to maintain SSC homeostasis ${ }^{115}$. Notably, Sertoli cells form junctions to create the blood-testis barrier (BTB), which divides the seminiferous epithelium into the basal and adluminal compartments. This division is crucial, as it helps to keep circulating toxicants, systemic immune components, and pathogens away from differentiating germ cells ${ }^{116}$.

SSCs are undifferentiated, whereas outside the BTB, up to the preleptotene stage $^{117}$, they remain spermatogonium, but as they progress inwards, SSCs mature towards primary and secondary spermatocytes before becoming spermatids and undergoing spermiogenesis, to ultimately become spermatozoa $^{118}$. Leydig cells are interstitial and produce testosterone to maintain spermatogenesis ${ }^{119}$. Testicular macrophages are the most heterogeneous and abundant testicular immune cells; they are phagocytic towards cell debris, foreign particles, and invading pathogens and help to maintain the immunoprivileged state within the testis, increasing in number during inflammation. Other testicular cell types include endothelial cells ${ }^{120}$, which aid in SSC renewal through the expression of glial-derived neurotrophic factor, fibroblast growth factor 2, stromal cell-derived factor 1, macrophage inflammatory protein 2 and insulin-like growth factor binding protein $2\left(\mathrm{REF}^{121}\right)$; and myoid cells ${ }^{120}$, which provide ultrastructure and express leukaemia inhibitory factor to help maintain SSC homeostasis ${ }^{122}$. Although all stages of spermatogenesis can be indirectly affected by viral interaction with testicular cells that provide support during proliferation, differentiation and maturation, spermatogonium - which sit outside the BTB - might be at an increased risk of direct viral interaction.

\section{Viral interaction with the testis}

Viral infections and their induced immune response are poorly understood aetiological factors that can functionally impair male reproduction, via effects on the testis and epididymis ${ }^{123,124}$. Viruses can directly affect spermatozoa, resulting in sperm death, reduction in sperm counts and decreased motility, or can act indirectly by inducing inflammatory cytokine production, inhibiting hormone production and altering the function of the genital organs ${ }^{125}$.

Viral entry. Viral infection of any of the main testicular cell types can negatively affect sperm output and quality (FIG. 3), via mechanisms including BTB breakdown and immune entry, hormone alteration, or a direct effect on spermatogonia ${ }^{126}$.

Viral entry into the testis normally occurs haematogenously. The BTB provides protection and immune privilege for germ cells; however, some viruses, such as Zika and HIV ${ }^{127,128}$, can pass through the BTB, eliciting an immune response ${ }^{129}$. The BTB is markedly different from other cell barriers, such as the blood-brain barrier and the pulmonary epithelial barrier: the BTB is much tighter than most barriers and is made up of multiple types of co-functioning junctions, unlike other barriers that are exclusively comprised of tight junctions ${ }^{130}$.

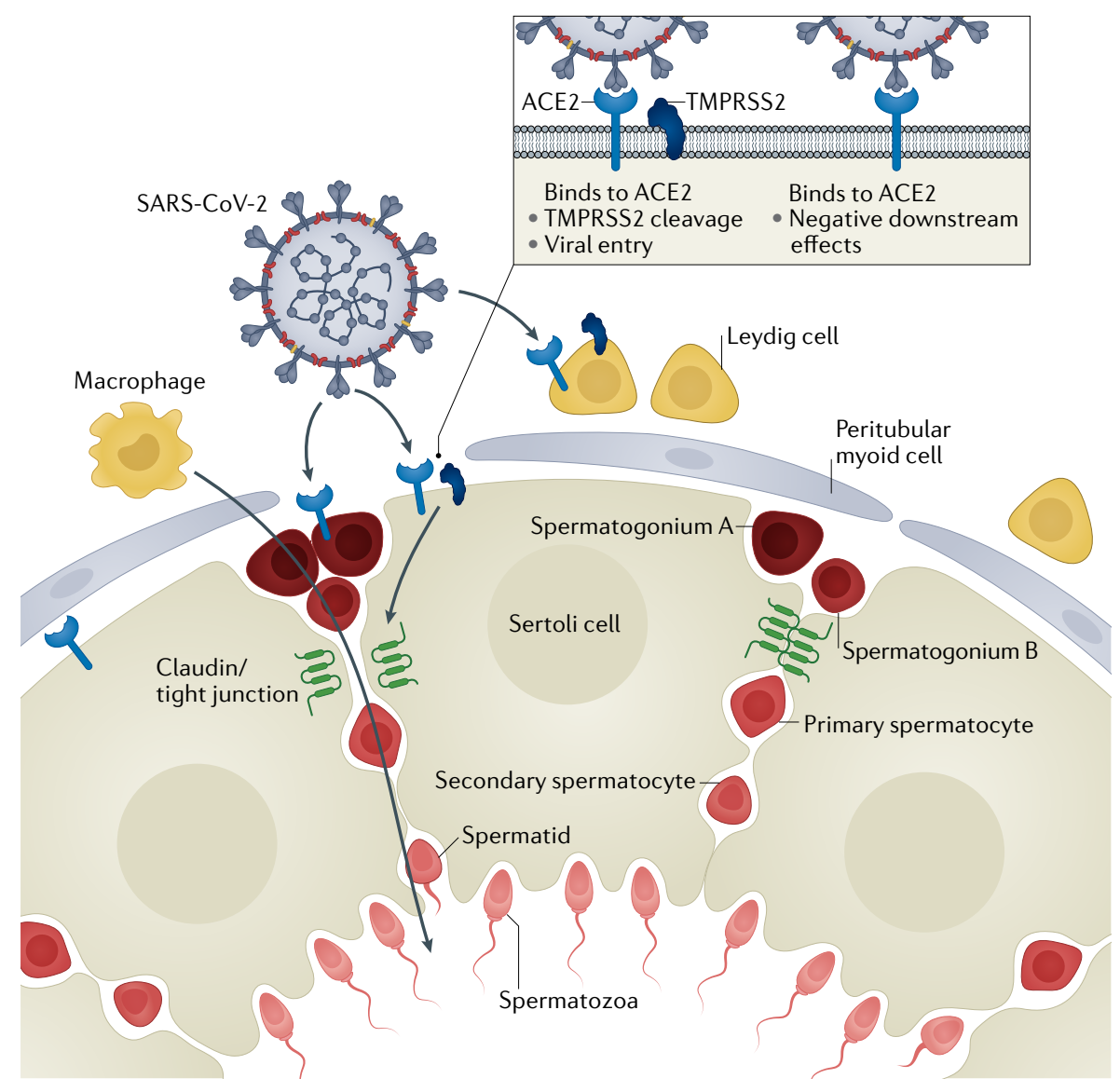

Fig. 3 | Effects of SARS-CoV-2 on the testis. Viral entry could occur in any cell type that has been shown to co-express angiotensin-converting enzyme 2 (ACE2) and transmembrane protease serine 2 (TMPRSS2) and might also be able to affect cells that only express ACE2. In the testis, every cell type except for spermatocytes and spermatids express ACE2. The spermatogonial stem cells and spermatogonia express both ACE2 and TMPRSS2, putting them at risk of SARS-CoV-2 infection. Additionally, with so many testicular cells expressing ACE2, SARS-CoV-2 could cause considerable damage, even without directly infecting testicular cells. 
Table 1 | Expression of ACE2 and TMPRSS2 in male reproductive cells

\begin{tabular}{lcc|}
\hline Cell type & ACE2 & TMPRSS2 \\
\hline Non-testicular & $\checkmark$ & $\checkmark$ \\
\hline Testis & $\checkmark$ & $\checkmark$ \\
\hline Leydig & $\checkmark$ & $\times$ \\
\hline Sertoli & $\checkmark$ & $\times$ \\
\hline Myoid & $\checkmark$ & $\times$ \\
\hline Stromal & $\checkmark$ & $\times$ \\
\hline Spermatogonial stem & $\checkmark$ & $\checkmark$ \\
cells & & \\
\hline Spermatogonia & $\checkmark$ & $\checkmark$ \\
\hline Spermatocyte & $\times$ & $\checkmark$ \\
\hline Spermatids & $\times$ & $\checkmark$ \\
\hline
\end{tabular}

ACE2, angiotensin-converting enzyme 2: TMPRSS2, transmembrane protease serine 2 .

However, the BTB also has some similarities to the epithelial barriers found in the lungs and brain. The tight junction, although not the only barrier in the BTB, is still a mainstay of the barrier; furthermore, the BTB is much more dynamic in nature than barriers found elsewhere ${ }^{130}$. Additionally, the BTB can be modulated by viruses, notably Zika virus $^{131,132}$. SARS-CoV-2 has been shown to disrupt and pass through both epithelial and endothelial barriers ${ }^{133}$, such as those found in the lungs and brain ${ }^{134-136}$, demonstrating a potential means by which SARS-CoV-2 can disrupt normal BTB function, potentially resulting in immune cell infiltration into the seminiferous tubules ${ }^{127}$.

ACE2 and TMPRSS2 expression. For SARSCoV-2 viral entry to occur, $A C E 2$ and TMPRSS2 must be co-expressed in cells. Both are primarily expressed in bronchial transient cells, especially alveolar type 2 cells ${ }^{137}$; thus, the respiratory tract is often the first organ system to be affected and usually incurs the most damage. While in the lungs, SARS-CoV and SARS-CoV-2 show viral targeting of ACE2 expressive cells such as alveolar epithelial cells, vascular endothelial cells and macrophages ${ }^{138,139}$. Although the full mechanism for COVID-19 pathology is not understood, the destruction of infected cells, breakdown of barriers and binding of ACE2 are fundamental ${ }^{140-143}$.

The data are conflicting regarding the exact expression of ACE2 and TMPRSS2 in the testis (TABLE 1) despite both being present $^{144,145}$. One study has suggested limited expression of ACE2 and TMPRSS2 in testis tissue and no overlapping expression of these genes in testicular cells ${ }^{145}$, indicating that viral entry into testicular cells is unlikely to occur ${ }^{146}$. However, other studies have shown that ACE2 is expressed in the myoid cells, Leydig cells, Sertoli cells and spermatogonia $^{72,147-152}$, indicating that these cell types could be highly susceptible to SARS-CoV-2 (TABLE 1). TMPRSS2 is shown to be expressed in SSC, spermatogonia, spermatocytes and spermatid cells ${ }^{72,149}$. ACE2 and TMPRSS2 are both expressed in many secondary sex organs, including the prostate, seminal vesicles and adrenal glands ${ }^{59,72,85,105,145}$. Notably, only one study ${ }^{153}$ has failed to show co-expression of ACE2 and TMPRSS2 in any male reproductive tissues (TABLE 1). Additionally, substantial inconsistencies are seen between mRNA and protein presence of ACE2 and TMPRSS2 $\left(\right.$ REF $\left.^{154}\right)$. In addition, the presence of promiscuous proteases and extracellular vesicular TMPRSS2 $\left(\right.$ REF. $^{75}$ ) means that infection might not solely depend on ACE2 and TMPRSS2 co-expression, requiring only ACE2. Furthermore, RAAS involvement in the testis means that direct infection of testicular cells might not be necessary for the disease to decrease testicular function.

Hormonal implications. Alongside the risk of direct infection of Leydig cells, the hypothalamic-pituitary-gonadal (HPG) axis could also be dysregulated by SARS-CoV-2 infection, resulting in altered levels of $\mathrm{FSH}$, LH and testosterone, which can potentially lead to spermatogenic impairment, hypogonadism and infertility ${ }^{155}$ (FIG. 4). Many endocrine organs, including the pituitary, thyroid, hypothalamus, pancreas, adrenal glands, pancreas, ovaries and testis, express ACE2 and TMPRSS2 $\left(\mathrm{REFS}^{156-158}\right)$. Although hypothalamic SARS-CoV and SARS-CoV-2 infection could theoretically result in decreased $\mathrm{GnRH}$, affecting gonadal hormone levels, this hypothesis has yet to be observed $^{155}$. FSH and LH levels increase with COVID severity ${ }^{159,160}$, possibly indicating inflammatory activation of gonadotropinproducing cells ${ }^{155}$. The hypothalamicpituitary-adrenal (HPA) and HPG axes have a reciprocal relationship, whereby they function in a tandem, flexible, and bidirectional manner and any insult to one will impact the other ${ }^{161}$. Additionally, the ACE2-expressive adrenal gland, which has a major role in the RAAS and HPA axis, is negatively affected by both SARS-CoV and SARS-CoV-2 infections, further implicating hormone disruption, possibly through hypothalamus and pituitary interactions ${ }^{162,163}$.

\section{Clinical studies in patients with COVID-19}

Many viruses such as HIV, hepatitis B and C, mumps, Epstein-Barr, papilloma and, notably, SARS-CoV, have been shown to cause testicular dysfunction or inflammation (orchitis) $^{164-166}$. SARS-CoV-2 displays similar pathology to SARS-CoV and could cause similar clinical effects, such as germ cell death, orchitis and immune intrusion ${ }^{165}$. Several case reports and studies have noted testicular pain and orchitis associated with SARS-CoV-2 infection ${ }^{167,168}$. Ediz et al. ${ }^{169}$ noted that $10.98 \%$ of 91 male patients with COVID-19 reported testicular pain, and Pan and colleagues ${ }^{145}$ reported that $19 \%$ of 34 male patients with COVID-19 displayed testicular discomfort suggestive of orchitis. In addition, Kim et al. ${ }^{170}$ presented a clinical report of a patient with testicular and abdominal pain associated with COVID-19, whilst Bridwell and colleagues ${ }^{171}$ and Gagliardi et al. ${ }^{172}$ presented clinical cases of bilateral orchitis and orcho-epididymitis, respectively. A report by Chen and colleagues $^{173}$ noted that $22.5 \%$ of 142 male patients had acute orchitis, epididymitis, or epididymo-orchitis associated with COVID-19 and also observed that scrotal infection risk increased with age, with $53.3 \%$ of patients over 80 years experiencing testicular symptoms. They also noted that the risk of epididymo-orchitis increased with severity of infection $(P=0.037)$. Furthermore, a study by Falahieh and co-workers, which observed 20 male patients with COVID-19 at day 14 and day 120 after infection, noted a $34.83 \%$ reduction in malondialdehyde and a $31.52 \%$ increase in total antioxidant capacity 120 days after infection. After 14 days a $33.1 \%$ increase in sperm DNA fragmentation, an increase in leukocytes, and progressive and total sperm motility below the WHO criteria were noted, all of which had returned to normal levels 120 days after infection ${ }^{174}$. However, the majority of men with COVID-19 do not report testicular pain.

Testicular and epididymal autopsy sections from six patients with COVID-19 showed signs of orchitis characterized by interstitial oedema, congestion, red blood cell exudation, increased concentration of $\mathrm{CD} 3 / \mathrm{CD} 8^{+}$, IgG within the seminiferous tubule, thinning of the seminiferous tubules and a significant increase in apoptotic cells within the seminiferous tubule $(P=0.018)^{175}$. Semen collected from 23 patients with mild or ordinary cases of COVID-19 showed that $39.1 \%$ had oligozoospermia and $60.9 \%$ had increased seminal leukocytes. The patients also had decreased sperm concentration and increased IL-6, TNF and MCP1 compared with men in the control group ${ }^{175}$. Furthermore, assessment of 81 men with moderate-to-severe SARS-CoV-2 infection 
showed significantly elevated serum LH levels $(P<0.0001)$ alongside significantly decreased ratios of serum testosterone: $\mathrm{LH}$ $(P<0.0001)$ and FSH:LH $(P<0.0001)^{160}$. Salciccia et al. and Rastrelli et al. both observed reduced total testosterone in patients with severe COVID-19 and showed a negative correlation with biochemical risk factors such as neutrophil count, lactate dehydrogenase, C-reactive protein, IL-6, D-dimer, $\mathrm{pH}$ and procalcitonin ${ }^{176,177}$. Similar effects have been brought on by SARS-CoV ${ }^{178}$. However, although hormonal changes were observed, none of these studies assessed the long-term effects on sperm production in the affected patients.

Reports of testicular discomfort and altered hormone levels in patients with COVID-19 indicate that SARS-CoV-2 might be able to infect testicular cells to directly affect testicular function. Viral presence in semen is a potential indicator of viral entry into the testis through the BTB, although whether SARS-CoV-2 is able to penetrate the $\mathrm{BTB}$ remains unclear ${ }^{179}$. Although presence of the SARS-CoV-2 virus in semen is debated, two groups have detected viral RNA in semen ${ }^{145,180-182}$. SARS-CoV-2 presence in the semen would suggest the possibility of sexual transmission of the virus and, importantly, a direct effect on the sperm itself, which are known to express and house ACE2 and TMPRSS2 (REF. ${ }^{183}$ ).

Testicular origin - rather than penetration of the BTB - is one explanation for viral presence in semen. In this scenario, viral entry might originate from other sources, such as the epididymis, seminal vesicles, prostate and urethra ${ }^{184}$, particularly as expression of TMPRSS2 (and other proteases) has been shown in the seminal vesicles and prostate, as well as the kidneys ${ }^{185,186}$.

Notably, although viral presence in semen is concerning, it does not necessarily indicate a negative effect on fertility. Even so, semen testing should be performed in future studies to ensure that SARS-CoV-2 is not present in the semen and, at the time of writing, many reproductive clinicians have suspended fertility treatments for infertile couples until more evidence is obtained ${ }^{187}$.

Clinical evidence suggesting widespread infection throughout several organ systems related to reproductive function, alongside the reports of testicular pain, orchitis and hormonal changes, justify concerns of a possible effect of SARS-CoV-2 on male fertility ${ }^{157,160,173,175,180}$. Moreover, although the exact testicular expression of ACE2 and TMPRSS2 is debated, their testicular presence has been observed for 20 years $^{188,189}$. The viral modulation of ACE2 and TMPRSS2 through comorbidities and environmental factors ${ }^{190}$ in specific cell types, both within and outside the testis and the BTB, leads to various pathological conditions, such as changes in hormone levels, BTB breakdown, immune response, or direct effects on the germ line, all of which have the potential to affect male fertility.

\section{Models of potential testicular effects of SARS-CoV-2}

The conflicting reports regarding SARS-CoV-2 entry into the testis cells mean that various informative models need to be considered for future studies in order to rigorously examine the potential effects of SARS-CoV-2 infection on male fertility. A comprehensive approach is essential as evidence of possible long-term effects of SARS-CoV-2 on many organ systems is increasing. The primary need must be to elucidate viral entry into the testis and, if this is confirmed, by what mechanism. A combination of animal, in vitro and cadaver models, guided by data from cohort and clinical studies, will be advantageous (FIG. 5). Animal models can be used to cheaply and efficiently pinpoint at-risk organ systems, whereas in vitro models can be used to investigate how specific testicular cell types might be affected by SARS-CoV-2 infection.

\section{Cohort studies}

For the clinical data to be useful, patients must be segregated by their age and disease status, most notably asymptomatic and symptomatic. As more information arises regarding the long-term health consequences of COVID-19, the formation of clinical cohorts will become even more important. Sperm and blood serum samples will need to be taken throughout the course of the infection and through several sperm production cycles after viral clearance. These time points will be key to observing any changes in sperm parameters and morphology, hormone levels and immune responses throughout infection, and to determine whether any of these changes persist after viral clearance.

One pilot cohort study of 69 male patients with COVID-19 noted a significant change in sperm parameters in patients with mild and moderate COVID-19: semen volume $(P<0.001)$, sperm concentration $(P=0.008)$, total sperm number $(P=0.001)$, progressive motility $(P<0.001)$, total motility $(P<0.001)$ and vitality $(P=0.001)^{191}$. The conclusions drawn from this study could have been improved through the addition of more outputs such as systemic hormone

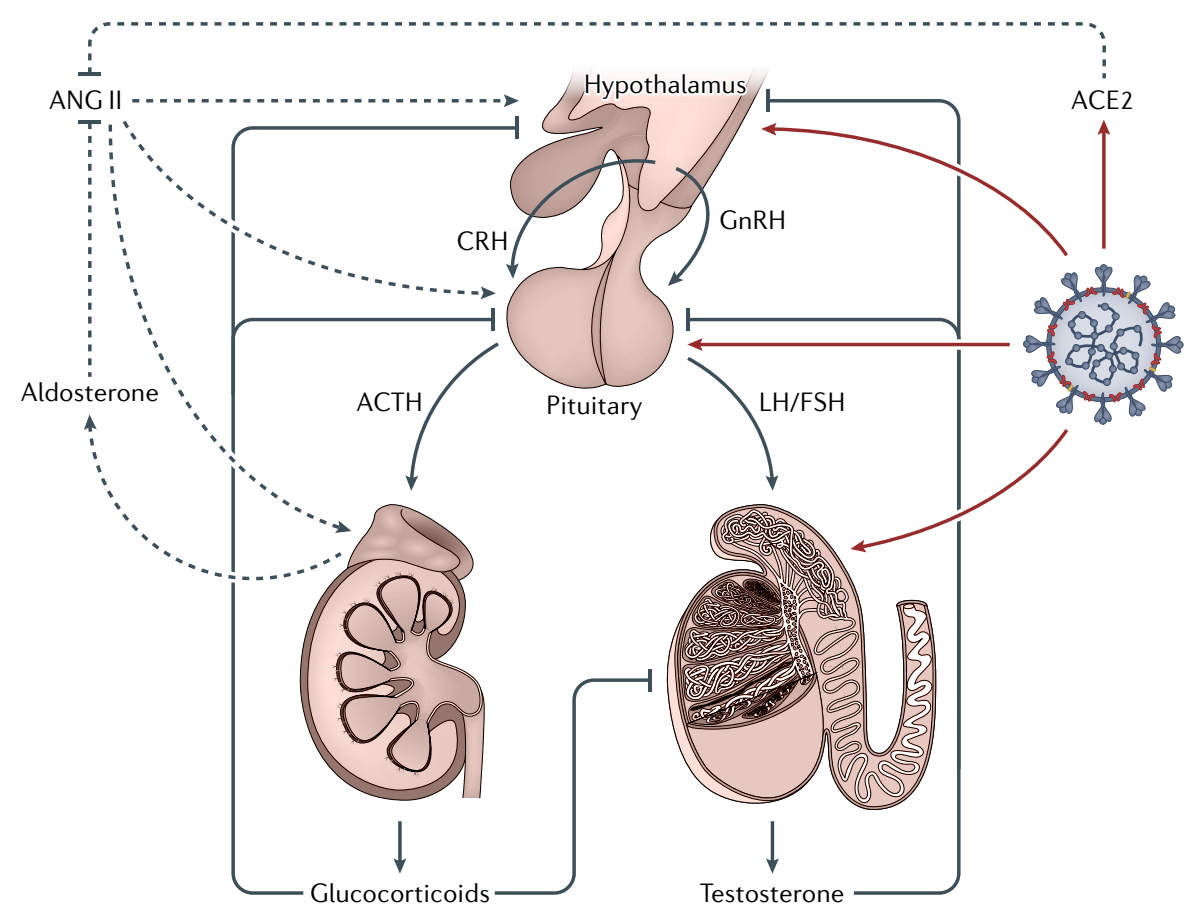

Fig. 4 | Effects of SARS-CoV-2 on hormone production. Through angiotensin-converting enzyme 2 (ACE2) inhibition, SARS-CoV-2 infection might alter hormone production. SARS-CoV-2 ACE2 inhibition can cause renin-angiotensin-aldosterone system-mediated overactivation of the hypothalamic-pituitary-adrenal axis, which can interfere with the hypothalamic-pituitary-gonadal axis. SARS-CoV-2 can also directly affect the hypothalamic-pituitary-gonadal axis. 
levels, blood pressure, morphological analysis and characterization of immune response; however, it provides a promising springboard for further studies.

Unfortunately, these cohort studies cannot provide any mechanistic data or solid evidence of viral presence in the testis, as tissue samples, in the form of testicular biopsy samples, would be required to confirm SARS-CoV-2 in testicular tissue, but cohort data will be vital for establishing the long-term implications of SARS-CoV-2 infection for male fertility.

\section{Post-mortem studies}

Post-mortem studies have a long tradition. Specifically in coronaviruses, autopsy reports for SARS and MERS were essential for elucidating their pathology and will be necessary to fully understand the reproductive pathology of SARS-CoV-2 $\left(\right.$ REFS $\left.^{166,192}\right)$. Only a small number of SARS-CoV-2 patient autopsy studies have been published to date, only ten have examined testicular tissue ${ }^{193-201}$. One of these performed post-mortem examinations on the testis of 12 men who had died with COVID-19. Of these 12 men, 1 displayed normal histology, 2 mild testicular injury,
5 moderate injury and 4 had severe injury. In the 11 patients with abnormal histology, Sertoli cells showed swelling, vacuolation and cytoplasmic rarefaction, as well as detachment from tubular basement membranes, and loss and sloughing into lumens of the intratubular cell mass. The study also illustrated substantial seminiferous tubular injury, reduced Leydig cells and mild lymphocytic inflammation. However, SARS-CoV-2 virus was not found to be present in the testes ${ }^{195}$.

A study of five patients aged 51-83 years who had died from COVID-19 showed germ cell sloughing into the lumen, seminiferous tubules characterized in a similar manner to Sertoli-cell-only syndrome, increased apoptotic cells, lymphocyte and macrophage infiltration, and - strikingly - SARS-CoV-2 presence in testicular cells using $\mathrm{S} 1$ antibody staining and the identification of coronavirus-like particles in the interstitial space of the testis providing direct evidence of testicular entry and attack by SARS-CoV-2 (REF. $\left.{ }^{200}\right)$. Similarly, post-mortem examinations on 6 men who died with COVID-19 showed that 3 of them had impaired spermatogenesis ${ }^{201}$. In one patient, transmission electron microscopy
(TEM) showed the presence of SARS-CoV-2 in the testes and haematoxylin and eosin (H\&E) staining demonstrated macrophage and leukocyte infiltrations in the same patient. Immunofluorescence studies in all six patients revealed a direct association between increased ACE2 levels $(P<0.05)$ and spermatogenic impairment ${ }^{201}$.

Further studies are needed to determine whether SARS-CoV-2 has direct effects on testicular dysfunction or whether the virus acts indirectly through secondary mechanisms such as elevated blood pressure, fever or inflammation triggered by SARS-CoV-2 infection ${ }^{202}$. However, post-mortem studies are associated with several limitations. For example, only patients who had severe infections are studied, which might not reflect accurate pathology in the majority of patients. Furthermore, many of these patients are likely to have other underlying comorbidities and risk factors that have predisposed them to severe infection as well as independent effects on fertility. Finally, death and organ collection generally occurs days to weeks after acute infection and viral clearance could have occurred by the time of organ collection.

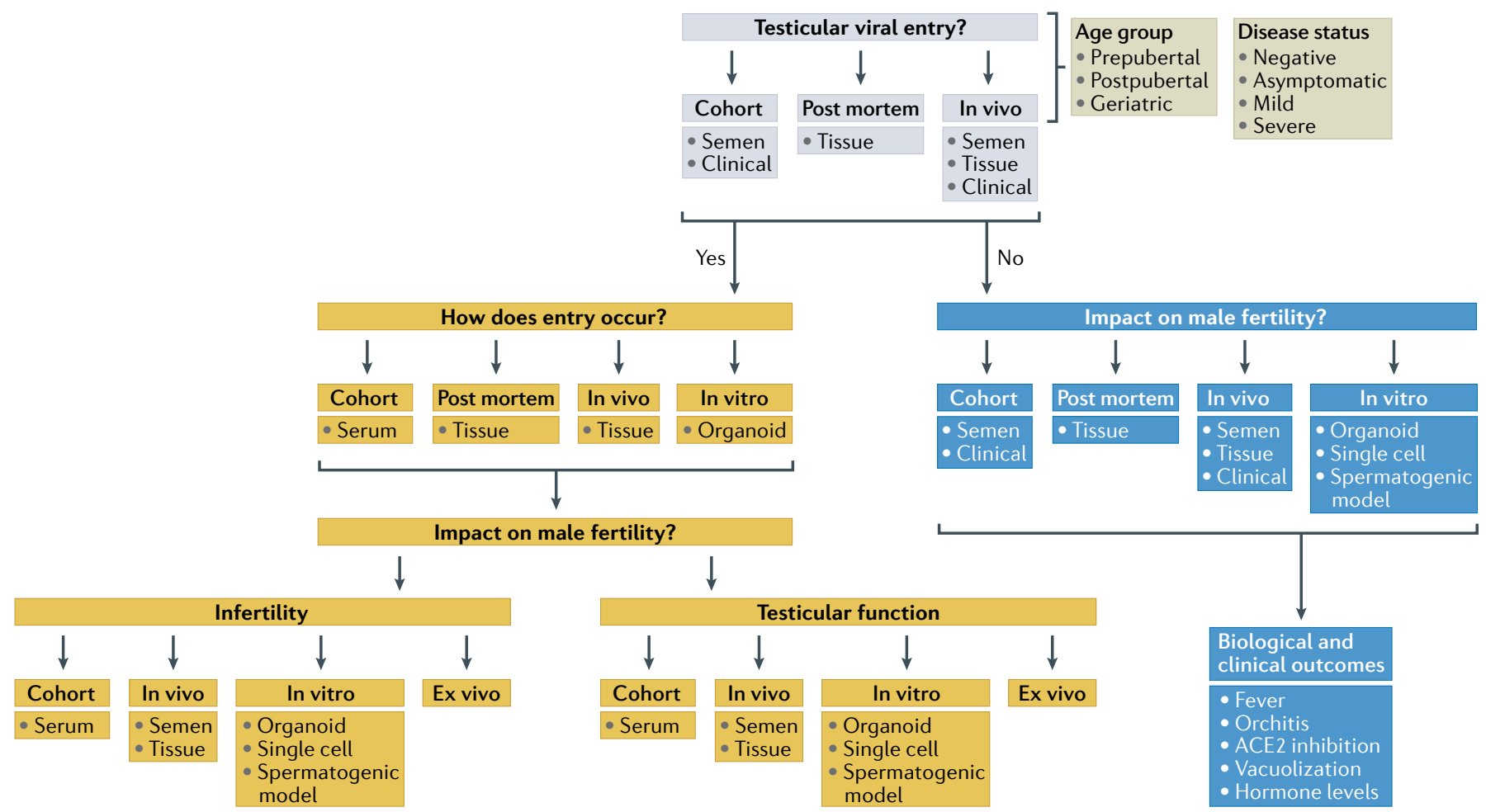

Fig. 5 | Proposed flow chart for evaluating effects of SARS-CoV-2 on male fertility. A systematic approach is essential to guide research. To understand possible effects on male fertility, the first step is to determine viral presence in the testes or semen, using human cohort and post-mortem studies alongside in vivo animal models. In clinical studies, patient cohorts should be divided primarily by their age and disease status. If viral entry is observed, a mechanism for viral entry and possible effects on male fertility and testicular function can then be investigated. If viral entry is not observed, this does not rule out an effect on testicular function, which will still require investigation, owing to concerns raised by clinical data and viral involvement in the renin-angiotensinaldosterone system pathway, which could have indirect effects on fertility. 


\section{In vivo models}

Alongside clinical and cadaver data, animal models are essential for researching disease progression, pathogenesis and immunological response. An optimal animal model of viral effects on male fertility has similar host-pathogen interactions and disease progression to humans and should enable the measurement of parameters such as clinical symptoms, viral growth and spread, and immune response $\mathrm{e}^{203,204}$. Thus, various animal models are required to expand pathophysiological relevance and for specific research stages. The animal models that are currently being used to research SARS-CoV-2 were vital for studying SARS and MERS biology; the best-characterized models in use are mice, ferrets, hamsters and non-human primates (NHPs). However, many of these animals display clinical symptoms of SARS-CoV-2 that are much milder and shorter than humans ${ }^{205}$.

Mice were used for studying both SARS-CoV and MERS ${ }^{206}$; human ACE2 (hACE2) transgenic mice have been shown to better model SARS and MERS infection than wild-type mice ${ }^{207}$. SARS-CoV-2 infection in hACE2 transgenic mice was shown to cause weight loss, viral replication in the lungs, interstitial pneumonia, macrophage infiltration and accumulation, interstitial lymphocyte infiltration and viral antigen presence in bronchial epithelial cells, macrophages and alveolar epithelia. None of these pathological conditions was observed in wild-type mice infected with SARS-CoV-2 (REF. $\left.{ }^{208}\right)$. The hACE2 transgenic model is likely to be valuable for evaluating routes of infection, barrier breakdown, therapies and vaccines of COVID-19. Additionally, the hACE2 transgenic mouse model provides a means of quickly observing the effect of ACE2 inhibition on fertility, the possible degradation of the BTB and viral impact on testicular somatic cells. Ferrets and Syrian golden hamsters are often used to study airborne viruses, particularly SARS, as they display human-like pulmonary characteristics ${ }^{209,210}$. One study has found viral RNA in the testes of intranasally infected hamsters up to 1 month after infection ${ }^{211}$. However, despite their consistent use in modelling pulmonary viral infections, including SARS-CoV-2, their use in studies of male fertility is minimal. Owing to kinetic and biological differences in spermatogenesis between rodents, mustelids and humans, these models cannot be recommended for standalone use in the study of SARS-CoV-2 and spermatogenesis. Furthermore, animal models are burdened with ethical dilemmas as well as money and time constraints. However, as animals are able to model organs and organ systems better than in vitro models, they remain a suitable model for viral entry, BTB damage and effects on testicular somatic cells.

NHPs have a close phylogenetic and physiological relationship with humans ${ }^{212}$; they are remarkably similar in their susceptibility to infectious disease, viral replication and immunological response $\mathrm{e}^{213}$ and are, therefore, used to model viral pathogenesis, male fertility and their intersection. Various NHP models were successfully used to uncover SARS and MERS pathogenesis ${ }^{214,215}$ and will be useful for elucidating SARS-CoV-2 infection. Although SARS-CoV-2 infection presents with less severe symptoms in NHPs than in humans, a more relevant pathology can be replicated by repeated infections. Additionally, similarities between human and NHP SARS-CoV-2 pathology have been reported ${ }^{216}$. Rhesus macaques and African green monkeys were both shown to display a COVID-19-like disease, which will be useful for elucidating human pathology $\mathrm{y}^{216,217}$. Additionally, historical use of NHPs to model viruses that are known to affect male fertility, such as Zika and mumps ${ }^{218,219}$, suggest that NHPs will be a valuable candidate system for studying SARS-CoV-2 and male fertility.

\section{In vitro models}

Although animal models are extremely useful, they do not fully recapitulate human processes such as human spermatogenesis; a human-derived in vitro model is necessary to fill these gaps. Two-dimensional culture systems have enabled insights into germ cell, somatic cell, and extracellular matrix interactions and the effects of growth factors, hormones and viruses ${ }^{220,221}$; however, such monolayer systems often display irrelevant physiology and cell communications that fail to mimic human biological responses ${ }^{222}$. Organoids derived from human primary or stem cells represent a more biologically relevant system than most in vivo and $2 \mathrm{D}$ culture systems ${ }^{223}$ and are useful for modelling viral infections ${ }^{224}$. Several human testicular organoids have been

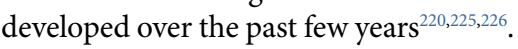
In 2019, the generation of human testicular organoids using a microwell culture system was reported $^{222}$. These organoids display testis-specific morphology and tight junction protein expression, and response to retinoic acid was similar to that observed in the testis in vivo. Germ cells displayed reduced levels of autophagy compared with those seen in 2D models, indicating reduced cellular stress. Overall, this model seems promising for the study of the effect of SARS-CoV-2 on male fertility ${ }^{222}$. Although organoids have been used to model SARS-CoV-2 infection in the brain, they have yet to be used for testicular cells $^{227}$. However, many of these organoids cannot provide an accurate view of viral pathogenicity as they fail to reproduce the complex organization of the testis and recapitulate spermatogenesis.

Testicular explants have been used to show Zika infection of testicular tissue and germ cells, but not widely in SARS-CoV-2 $\left(\mathrm{REF}^{228}\right)$. One study has shown viral replication in hamster testes using an ex vivo infection model ${ }^{211}$. However, ex vivo models have been used to model SARS-CoV-2 infection in the lungs ${ }^{229,230}$. This type of model enables study of an organ's natural physiological and pathological environment, including tissue architecture, cell-cell interactions and local immune response. However, these models are best suited for short-term studies and rely on organ donors.

If SARS-CoV-2 is shown to pass through or degrade the BTB or is demonstrated to be present in patient semen, determining the effects of interactions between developing sperm cells and the virus will be essential. However, most of these spermatogenic models discussed above fail to recapitulate human in vivo effects such as germ cell death and cannot sustain chronic viral exposure, which is necessary for studying the effects of viral intrusion. An unbiased high-throughput format has been reported, which mirrored aspects of human spermatogenesis and mimicked the effects of environmental exposures in vivo ${ }^{231-233}$. Although this model has so far been used primarily for studying environmental toxicants, such as perfluoroalkyl and polyfluoroalkyl substances and polybrominated bipheny ${ }^{232,234}$, it is also well suited to observing the effects of SARS-CoV-2 and other viruses on spermatogenesis, particularly SSCs and early spermatogenic stages. However, as this model represents only spermatogenesis and lacks the somatic cell niche, its utility is limited to studying only the direct effects of SARS-CoV-2 on spermatogenic cells. Additionally, the model is limited by low haploid generation and lacks the capability to produce fully differentiated sperm.

\section{Conclusions}

The focus of SARS-CoV-2 research has so far been on the lungs and immune response, as these two systems are highly engaged during infection. Although little research has 
investigated effects on male fertility, several studies have reported SARS-CoV-2-induced orchitis, altered hormone levels, testicular damage and the possible presence of the virus in sperm. As increasing data indicate the long-term effects of COVID on other organ systems, long-term effects on the testis will also need to be examined.

Whether these symptoms arise from the direct effects of SARS-CoV-2 on the testis or whether they are mediated by other mechanisms, such as immune response and inflammation, remains to be determined; alternatively, underlying risk factors for SARS-CoV-2 could even be the ultimate cause. It is essential to remember that any disease state or environmental factor that dysregulates furin, ACE2 or TMPRSS2 can affect SARS-CoV-2 infection and its intersection with male fertility. The primary proteins involved in SARS-CoV-2 pathology, particularly ACE2 and TMPRSS2, are expressed throughout the body, including in the testis. Thus, their infection or negative inhibition by SARS-CoV-2 could have severe consequences for male fertility. Although the RAAS is involved in male fertility, the extent to which ACE2 and TMPRSS2 are expressed in the testes is uncertain and requires more research. Several in vivo and in vitro models show promise for studying the effects of SARS-CoV-2 on male fertility. Tandem use of a variety of models alongside clinical data will be necessary to fully elucidate the effects of SARS-CoV-2 infection on male fertility.

As long-term sequelae of SARS-CoV-2 begin to be examined, viral effects on sperm production and male fertility should be considered to guide research and to modify clinical advice for patients. Multiple justifications exist for a potentially detrimental effect of SARS-CoV-2 on male fertility; however, a multifaceted approach is required for validation.

R. Clayton Edenfield (iD ${ }^{1,2}$ and Charles A. Easley IV (iD ${ }^{1,2}{ }^{2}$ 'Department of Environmental Health Science, College of Public Health, University of Georgia, Athens, GA, USA.

${ }^{2}$ Regenerative Bioscience Center, University of Georgia, Athens, GA, USA.

凶e-mail: cae25@uga.edu

https://doi.org/10.1038/s41585-021-00542-5

Published online 26 November 2021

1. Shereen, M. A., Khan, S., Kazmi, A., Bashir, N. \& Siddique, R. COVID-19 infection: origin, transmission, and characteristics of human coronaviruses. J. Adv. Res. 24, 91-98 (2020)

2. World Health Organization. WHO Coronavirus (COVID-19) Dashboard. World Health Organization https://covid19.who.int/ (2021).

3. Lithander, F. E. et al. COVID-19 in older people: a rapid clinical review. Age Ageing 49, 501-515 (2020).

4. Zheng, Z. et al. Risk factors of critical $\&$ mortal wCOVID-19 cases: a systematic literature review wand meta-analysis. J. Infect. 81, e16-e25 (2020).
5. AbdelMassih, A. F. et al. A multicenter consensus: a role of furin in the endothelial tropism in obese patients with COVID-19 infection. Obes. Med. 19 100281 (2020).

6. Fang, L., Karakiulakis, G. \& Roth, M. Are patients with hypertension and diabetes mellitus at increased risk for COVID-19 infection? Lancet Respir. Med. 8, e21 (2020).

7. AbdelMassih, A. et al. Obese communities among the best predictors of COVID-19-related deaths. Cardiovasc. Endocrinol. Metab. 9, 102-107 (2020).

8. Cevik, M., Bamford, C. G. G. \& Ho, A. COVID-19 pandemic - a focused review for clinicians. Clin. Microbiol. Infect. 26, 842-847 (2020).

9. Stasi, C., Fallani, S., Voller, F. \& Silvestri, C. Treatment for COVID-19: an overview. Eur. J. Pharmacol. 889, 173644-173644 (2020)

10. Zhang, J. J. et al. Clinical characteristics of 140 patients infected with SARS-CoV-2 in Wuhan, China Allergy 75, 1730-1741 (2020).

11. Mao, L. et al. Neurologic manifestations of hospitalized patients with coronavirus disease 2019 in Wuhan, China. JAMA Neurol. 77, 1-9 (2020).

12. Wu, P. et al. Characteristics of ocular findings of patients with coronavirus disease 2019 (COVID-19) in Hubei Province, China. JAMA Ophthalmol. 138, 575-578 (2020)

13. Nishiga, M., Wang, D. W., Han, Y., Lewis, D. B. \& Wu, J. C. COVID-19 and cardiovascular disease: from basic mechanisms to clinical perspectives. Nat. Rev. Cardiol. 17, 543-558 (2020).

14. Zheng, Y.-Y., Ma, Y.-T., Zhang, J.-Y. \& Xie, X. COVID-19 and the cardiovascular system. Nat. Rev. Cardiol. 17, 259-260 (2020)

15. Puelles, V. G. et al. Multiorgan and renal tropism of SARS-CoV-2. N. Engl. J. Med. 383, 590-592 (2020).

16. Trypsteen, W., Van Cleemput, J., Snippenberg, W. V., Gerlo, S. \& Vandekerckhove, L. On the whereabouts of SARS-CoV-2 in the human body: a systematic review. PLoS Pathog. 16, e1009037-e1009037 (2020).

17. Carfi, A., Bernabei, R. \& Landi, F., Gemelli Against COVID-19 Post-Acute Care Study Group. Persistent symptoms in patients after acute COVID-19. JAMA 324, 603-605 (2020)

18. Lopez-Leon, S. et al. More than 50 long-term effects of COVID-19: a systematic review and meta-analysis. Sci. Rep. 11, 16144 (2021).

19. Groff, D. et al. Short-term and long-term rates of postacute sequelae of SARS-CoV-2 infection: a systematic review. JAMA Netw. Open $\mathbf{4}$, e2128568-e2128568 (2021).

20. Weiss, S. R. \& Leibowitz, J. L. Coronavirus pathogenesis. Adv. Virus Res. 81, 85-164 (2011).

21. Mesel-Lemoine, M. et al. A human coronavirus responsible for the common cold massively kills dendritic cells but not monocytes. J. Virol. $\mathbf{8 6}$, 7577-7587 (2012).

22. Zhou, P. et al. A pneumonia outbreak associated with a new coronavirus of probable bat origin. Nature $\mathbf{5 7 9}$ 270-273 (2020)

23. Chen, N. et al. Epidemiological and clinical characteristics of 99 cases of 2019 novel coronavirus pneumonia in Wuhan, China: a descriptive study. Lancet 395, 507-513 (2020).

24. Zhu, Z. et al. From SARS and MERS to COVID-19. a brief summary and comparison of severe acute respiratory infections caused by three highly pathogenic human coronaviruses. Respir. Res. 21 224 (2020).

25. Liu, Y. et al. Viral dynamics in mild and severe cases of COVID-19. Lancet Infect. Dis. 20, 656-657 (2020).

26. Zhao, S. et al. Preliminary estimation of the basic reproduction number of novel coronavirus (2019nCoV) in China, from 2019 to 2020: a data-driven analysis in the early phase of the outbreak. Int. J. Infect. Dis. 92, 214-217 (2020).

27. Liu, Y., Gayle, A. A., Wilder-Smith, A. \& Rocklöv, J. The reproductive number of COVID-19 is higher compared to SARS coronavirus. J. Travel. Med. 27, taaa021 (2020).

28. Lipsitch, M. et al. Transmission dynamics and control of severe acute respiratory syndrome. Science 300 1966-1970 (2003)

29. Majumder, M. S., Rivers, C., Lofgren, E. \& Fisman, D. Estimation of MERS-coronavirus reproductive number and case fatality rate for the spring 2014 Saudi Arabia outbreak: insights from publicly available data. PLoS Curr. https://doi.org/10.1371/currents. outbreaks.98d2f8f3382d84f390736cd5f5fe 133c (2014).

30. V'kovski, P., Kratzel, A., Steiner, S., Stalder, H $\&$ Thiel, V. Coronavirus biology and replication: implications for SARS-CoV-2. Nat. Rev. Microbiol. 19 , 155-170 (2021).

31. Astuti, I. \& Ysrafil. Severe acute respiratory syndrome coronavirus 2 (SARS-CoV-2): an overview of viral structure and host response. Diabetes Metab. Syndr. 14, 407-412 (2020).

32. Li, F., Li, W., Farzan M \& Harrison, S. C. Structure of SARS coronavirus spike receptor-binding domain complexed with receptor. Science 309, 1864-1868 (2005).

33. $\mathrm{Xu}, \mathrm{X}$. et al. Evolution of the novel coronavirus from the ongoing Wuhan outbreak and modeling of its spike protein for risk of human transmission. Sci. China Life Sci. 63, 457-460 (2020)

34. Li, F. Structure, function, and evolution of coronavirus spike proteins. Annu. Rev. Virol. 3, 237-261 (2016).

35. Li, F. et al. Conformational states of the severe acute respiratory syndrome coronavirus spike protein ectodomain. J. Virol. 80, 6794-6800 (2006).

36. Yuan, Y. et al. Cryo-EM structures of MERS-CoV and SARS-CoV spike glycoproteins reveal the dynamic receptor binding domains. Nat. Commun. 8, 15092 (2017).

37. Perlman, S. \& Netland, J. Coronaviruses post-SARS update on replication and pathogenesis. Nat. Rev. Microbiol. 7, 439-450 (2009).

38. Wang, N. et al. Structure of MERS-CoV spike receptorbinding domain complexed with human receptor DPP4. Cell Res. 23, 986-993 (2013).

39. Walls, A. C. et al. Structure, function, and antigenicity of the SARS-CoV-2 spike glycoprotein. Cell 181 , 281-292.e286 (2020).

40. $\mathrm{Li}, \mathrm{W}$. et al. Angiotensin-converting enzyme 2 is a functional receptor for the SARS coronavirus. Nature 426, 450-454 (2003).

41. Raj, V. S. et al. Dipeptidyl peptidase 4 is a functional receptor for the emerging human coronavirus-EMC. Nature 495, 251-254 (2013).

42. Towler, P. et al. ACE2 X-ray structures reveal a large hinge-bending motion important for inhibitor binding and catalysis. J. Biol. Chem. 279, 17996-18007 (2004).

43. Wong, S. K., Li, W., Moore, M. J., Choe, H. \& Farzan, M. A 193-amino acid fragment of the SARS coronavirus $\mathrm{S}$ protein efficiently binds angiotensinconverting enzyme 2. J. Biol. Chem. 279, 3197-3201 (2004).

44. Chen, Y., Guo, Y., Pan, Y. \& Zhao, Z. J. Structure analysis of the receptor binding of 2019-nCoV. Biochem. Biophys. Res. Commun. 525, 135-140 (2020).

45. Glowacka, I. et al. Evidence that TMPRSS2 activates the severe acute respiratory syndrome coronavirus spike protein for membrane fusion and reduces viral control by the humoral immune response. J. Virol. 85 4122-4134 (2011).

46. Heurich, A. et al. TMPRSS2 and ADAM17 Cleave ACE2 differentially and only proteolysis by TMPRSS2 augments entry driven by the severe acute respiratory syndrome coronavirus spike protein. J. Virol. 88, 1293 (2014).

47. Hasan, A. et al. A review on the cleavage priming of the spike protein on coronavirus by angiotensinconverting enzyme- 2 and furin. J. Biomol. Struct. Dyn. 39, 3025-3033 (2020).

48. Shang, J. et al. Structural basis of receptor recognition by SARS-CoV-2. Nature 581, 221-224 (2020).

49. Millet, J. K., Jaimes, J. A. \& Whittaker, G. R. Molecular diversity of coronavirus host cell entry receptors. FEMS Microbiol. Rev. 45, fuaa057 (2020).

50. Hoffmann, M Kleine-Weber, H. \& Pöhlmann, S. A multibasic cleavage site in the spike protein of SARS-CoV- 2 is essential for infection of human lung cells. Mol. Cell 78, 779-784.e775 (2020)

51. Ranta, N. et al. The plasma level of proprotein convertase FURIN in patients with suspected infection in the emergency room: a prospective cohort study. Scand. J. Immunol. 82, 539-546 (2015).

52. Xia, S. et al. The role of furin cleavage site in SARSCoV-2 spike protein-mediated membrane fusion in the presence or absence of trypsin. Signal. Transduct. Target. Ther. 5, 92 (2020).

53. Duffy, S. Why are RNA virus mutation rates so damn high? PLoS Biol. 16, e3000003-e3000003 (2018).

54. $\mathrm{Li}$, O. et al. The impact of mutations in SARS-CoV-2 spike on viral infectivity and antigenicity. Cell 182 1284-1294.e1289 (2020).

55. Ozono, S. et al. SARS-CoV-2 D614G spike mutation increases entry efficiency with enhanced ACE2-binding affinity. Nat. Commun. 12, 848 (2021). 
56. Vöhringer, H. S. et al. Genomic reconstruction of the SARS-CoV-2 epidemic in England. Nature https:/ doi.org/10.1038/s41586-021-04069-y (2021).

57. Guruprasad, L. Human SARS CoV-2 spike protein mutations. Proteins 89, 569-576 (2021).

58. Qiao, Y. et al. Targeting transcriptional regulation of SARS-CoV-2 entry factors ACE2and TMPRSS2. Proc. Natl Acad. Sci. USA 118, e2021450118 (2021).

59. Lucas, J. M. et al. The androgen-regulated protease TMPRSS2 activates a proteolytic cascade involving components of the tumor microenvironment and promotes prostate cancer metastasis. Cancer Discov. 4, 1310-1325 (2014).

60. Younis, J. S., Skorecki, K. \& Abassi, Z. The double edge sword of testosterone's role in the COVID-19 pandemic. Front. Endocrinol. https://doi.org/10.3389/ fendo. 2021.607179 (2021).

61. Bilinska, K., Jakubowska, P., Von Bartheld, C. S. $\&$ Butowt, R. Expression of the SARS-CoV-2 entry proteins, ACE2 and TMPRSS2, in cells of the olfactory epithelium: identification of cell types and trends with age. ACS Chem Neurosci. 11, 1555-1562 (2020).

62. Dugail, I., Amri, E.-Z. \& Vitale, N. High prevalence for obesity in severe COVID-19: possible links and perspectives towards patient stratification. Biochimie 179, 257-265 (2020).

63. Holly, J. M. P., Biernacka, K., Maskell, N. \& Perks, C. M. Obesity, diabetes and COVID-19: an infectious disease spreading from the east collides with the consequences of an unhealthy western lifestyle. Front. Endocrinol. 11, 582870-582870 (2020).

64. Shibata, S. et al. Hypertension and related diseases in the era of COVID-19: a report from the Japanese Society of Hypertension Task Force on COVID-19. Hypertens. Res. 43, 1028-1046 (2020).

65. Bui, L. T. et al. Chronic lung diseases are associated with gene expression programs favoring SARS-CoV-2 entry and severity. Nat. Commun. 12, 4314 (2021).

66. Zipeto, D., Palmeira, J. d. F., Argañaraz, G. A \& Argañaraz, E. R. ACE2/ADAM17/TMPRSS2 interplay may be the main risk factor for COVID-19. Front. Immunol. https://doi.org/10.3389/ fimmu. 2020.576745 (2020)

67. Kočar, E., Režen, T. \& Rozman, D. Cholesterol, lipoproteins, and COVID-19: Basic concepts and clinical applications. Biochim. Biophys. Acta Mol. Cell Biol. Lipids 1866, 158849-158849 (2021).

68. Brake, S. J. et al. Smoking Upregulates angiotensinconverting enzyme- 2 receptor: a potential adhesion site for novel coronavirus SARS-CoV-2 (Covid-19). J. Clin. Med. 9, 841 (2020).

69. Wu, Q., Coumoul, X., Grandjean, P., Barouki, R. $\&$ Audouze, K. Endocrine disrupting chemicals and COVID-19 relationships: a computational systems biology approach. Preprint at medRxiv https://doi.org/ 10.1101/2020.07.10.20150714 (2020).

70. Braun, E. \& Sauter, D. Furin-mediated protein processing in infectious diseases and cancer. Clin. Transl. Immunol. 8, e 1073 (2019).

71. Hoffmann, M. et al. SARS-CoV-2 cell entry depends on ACE2 and TMPRSS2 and is blocked by a clinically proven protease inhibitor. Cell 181, 271-280.e278 (2020).

72. Sungnak, W. et al. SARS-CoV-2 entry factors are highly expressed in nasal epithelial cells together with innate immune genes. Nat. Med. 26, 681-687 (2020).

73. Zhao, M.-M. et al. Cathepsin L plays a key role in SARS-CoV- 2 infection in humans and humanized mice and is a promising target for new drug development. Signal. Transduct. Target. Ther. 6, 134 (2021).

74. Samavati, L. \& Uhal, B. D. ACE2, Much more than just a receptor for SARS-COV-2. Front. Cell. Infect. Microbiol. 10, 317 (2020)

75. Chi, M. et al. Dexmedetomidine promotes breast cancer cell migration through Rab 11-mediated secretion of exosomal TMPRSS2. Ann. Transl. Med. 8 531 (2020).

76. Kuba, K., Imai, Y. \& Penninger, J. M. Angiotensinconverting enzyme 2 in lung diseases. Curr. Opin. Pharmacol. 6, 271-276 (2006).

77. Takahashi, H. Upregulation of the renin-angiotensinaldosterone-ouabain system in the brain Is the core mechanism in the genesis of all types of hypertension. Int. J. Hypertens. 2012, 242786 (2012)

78. Okamura, A. et al. Upregulation of renin-angiotensin system during differentiation of monocytes to macrophages. J. Hypertens. 17, 537-545 (1999).

79. Paz Ocaranza, M. et al. Counter-regulatory reninangiotensin system in cardiovascular disease. Nat. Rev. Cardiol. 17, 116-129 (2020).

80. Iwai, M. \& Horiuchi, M. Devil and angel in the reninangiotensin system: ACE-angiotensin II-AT 1 receptor axis vs. ACE2-angiotensin-(1-7)-Mas receptor axis. Hypertens. Res. 32, 533-536 (2009)

81. Kuriakose, J., Montezano, A. C. \& Touyz, R. M ACE2/Ang-(1-7)/Mas1 axis and the vascular system vasoprotection to COVID-19-associated vascular disease. Clin. Sci. 135, 387-407 (2021).

82. Karnik, S. S., Singh, K. D., Tirupula, K. \& Unal, H. Significance of angiotensin 1-7 coupling with MAS 1 receptor and other GPCRs to the renin-angiotensin system: IUPHAR Review 22. Br. J. Pharmacol. 174 737-753 (2017)

83. Ingraham, N. E et al. Understanding the renin-angiotensin-aldosterone-SARS-CoV-axis: a comprehensive review. Eur. Respir. J. 56, 2000912 (2020).

84. Xiao, L., Sakagami, H. \& Miwa, N. ACE2: the key molecule for understanding the pathophysiology of severe and critical conditions of COVID-19: demon or angel? Viruses 12, 491 (2020)

85. Verdecchia, P., Cavallini, C., Spanevello, A. \& Angeli, F. The pivotal link between ACE2 deficiency and SARSCoV-2 infection. Eur. J. Intern. Med. 76, 14-20 (2020).

86. Imai, Y., Kuba, K. $\&$ Penninger, J. M. The discovery of angiotensin-converting enzyme 2 and its role in acute lung injury in mice. Exp. Physiol. 93, 543-548 (2008).

87. Zhang, H., Penninger, J. M., Li, Y., Zhong, N. \& Slutsky, A. S. Angiotensin-converting enzyme 2 (ACE2) as a SARS-CoV-2 receptor: molecular mechanisms and potential therapeutic target. Intensive Care Med. 46 586-590 (2020)

88. Ekholm, M., Kahan, T., Jörneskog, G., Brinck, J. $\&$ Wallén, N. H. Haemostatic and inflammatory alterations in familial hypercholesterolaemia, and the impact of angiotensin II infusion. J. Renin Angiotensin Aldosterone Syst. 16, 328-338 (2015).

89. Beyerstedt, S., Casaro, E. B. \& Rangel, É. B. COVID-19: angiotensin-converting enzyme 2 (ACE2) expression and tissue susceptibility to SARS-CoV-2 infection. Eur. J. Clin. Microbiol. Infect. Dis. 40 , 905-919 (2021)

90. Zapater, P., Novalbos, J., Gallego-Sandīn, S. Hernández, F. T. \& Abad-Santos, F. Gender differences in angiotensin-converting enzyme (ACE) activity and inhibition by enalaprilat in healthy volunteers. J. Cardiovasc. Pharmacol. 43, 737-744 (2004).

91. Komukai, K., Mochizuki, S. \& Yoshimura, M. Gender and the renin-angiotensin-aldosterone system. Fundam. Clin. Pharmacol. 24, 687-698 (2010).

92. Reyes, J. G. et al. The hypoxic testicle: physiology and pathophysiology. Oxid. Med. Cell Longev. 2012. 929285-929285 (2012)

93. Colli, L. G. et al. Systemic arterial hypertension leads to decreased semen quality and alterations in the testicular microcirculation in rats. Sci. Rep. 9, 11047 (2019).

94. Pacurari, M., Kafoury, R., Tchounwou, P. B. \& Ndebele, K. The renin-angiotensin-aldosterone system in vascular inflammation and remodeling Int. J. Inflamm. 2014, 689360 (2014).

95. Guo, J. H., Huang, Q., Studholme, D. J., Wu, C. Q. \& Zhao, Z. Transcriptomic analyses support the similarity of gene expression between brain and testis in human as well as mouse. Cytogenet. Genome Res. 111 , 107-109 (2005)

96. McGavern, D. B. \& Kang, S. S. Illuminating viral infections in the nervous system. Nat. Rev. Immunol. 11, 318-329 (2011)

97. Jackson, L., Eldahshan, W., Fagan, S. C. \& Ergul, A. Within the brain: the renin angiotensin system. Int. J. Mol. Sci. 19, 876 (2018)

98. Xia, H. \& Lazartigues, E. Angiotensin-converting enzyme 2 in the brain: properties and future directions. J. Neurochem. 107, 1482-1494 (2008)

99. Song, E. et al. Neuroinvasion of SARS-CoV-2 in human and mouse brain. J. Exp. Med. 218, e20202135 (2021).

100. Paterson, R. W. et al. The emerging spectrum of COVID-19 neurology: clinical, radiological and laboratory findings. Brain, 143, 3104-3120 (2020).

101. Castilho, A. C. S., Fontes, P. K., Franchi, F. F. Santos, P. H. \& Razza, E. M. Renin-angiotensin system on reproductive biology, renin-angiotensin system past, present and future. IntechOpen https://doi.org/ 10.5772/66997 (2017)

102. Gianzo, M. et al. Angiotensin II type 2 receptor is expressed in human sperm cells and is involved in sperm motility. Fertil. Steril. 105, 608-616 (2016).

103. Leal, M. C. et al. The role of angiotensin-(1-7) receptor Mas in spermatogenesis in mice and rats. J. Anat. 214, 736-743 (2009).
104. Leung, P. S. \& Sernia, C. The renin-angiotensin system and male reproduction: new functions for old hormones. J. Mol. Endocrinol. 30, 263-270 (2003).

105. Paul, M., Mehr, A. P. \& Kreutz, R. Physiology of local renin-angiotensin systems. Physiol. Rev. 86, 747-803 (2006).

106. Reis, A. B. et al. Angiotensin (1-7) and its receptor Mas are expressed in the human testis: implications for male infertility. J. Mol. Histol. 41, 75-80 (2010)

107. Valdivia, A. et al. Role of angiotensin-(1-7) via MAS receptor in human sperm motility and acrosome reaction. Reproduction 159, 241-249 (2020)

108. Campbell, D. J. Clinical relevance of local renin angiotensin systems. Front. Endocrinol. 5, 113-113 (2014).

109. Shibahara, H. et al. Activity of testis angiotensin converting enzyme (ACE) in ejaculated human spermatozoa. Int. J. Androl. 24, 295-299 (2001).

110. Illiano, E., Trama, F. \& Costantini, E. Could COVID-19 have an impact on male fertility? Andrologia 52, e13654-e13654 (2020)

111. Younis, J. S., Abassi, Z. \& Skorecki, K. Is there an impact of the COVID-19 pandemic on male fertility? The ACE2 connection. Am. J. Physiol. Endocrinol. Metab. 318, E878-E880 (2020).

112. Sèdes, L. et al. Cholesterol: a gatekeeper of male fertility? Front. Endocrinol. 9, 369-369 (2018).

113. Oatley, J. M. \& Brinster, R. L. The germline stem cell niche unit in mammalian testes. Physiol. Rev. 92, 577-595 (2012).

114. Kerr, J. B. Ultrastructure of the seminiferous epithelium and intertubular tissue of the human testis. J. Electron. Microsc. Tech. 19, 215-240 (1991).

115. Garcia, T. X. \& Hofmann, M. C. Regulation of germ line stem cell homeostasis. Anim. Reprod. 12, 35-45 (2015).

116. Mruk, D. D. \& Cheng, C. Y. Sertoli-Sertoli and Sertoligerm cell interactions and their significance in germ cell movement in the seminiferous epithelium during spermatogenesis. Endocr. Rev. 25, 747-806 (2004).

117. Ni, F.-D., Hao, S.-L. \& Yang, W.-X. Multiple signaling pathways in Sertoli cells: recent findings in spermatogenesis. Cell Death Dis. 10, 541 (2019).

118. Rato, L. et al. Metabolic regulation is important for spermatogenesis. Nat. Rev. Urol. 9, 330-338 (2012)

119. Smith, L. B. \& Walker, W. H. The regulation of spermatogenesis by androgens. Semin. Cell Dev. Biol. 30, 2-13 (2014)

120. Guo, J. et al. The adult human testis transcriptional cell atlas. Cell Res. 28, 1141-1157 (2018).

121. Bhang, D. H. et al. Testicular endothelial cells are a critical population in the germline stem cell niche. Nat. Commun. 9, 4379 (2018).

122. Mayerhofer, A. Human testicular peritubular cells: more than meets the eye. Reproduction 145 R107-R116 (2013).

123. Schuppe, H. C. et al. Chronic orchitis: a neglected cause of male infertility? Andrologia 40, 84-91 (2008).

124. Tortorec, A. L. et al. From ancient to emerging infections: the odyssey of viruses in the male genital tract. Physiol. Rev. 100, 1349-1414 (2020).

125. Liu, W., Han, R., Wu, H. \& Han, D. Viral threat to male fertility. Andrologia 50, e13140 (2018).

126. Dejucq, N. \& Jégou, B. Viruses in the mammalian male genital tract and their effects on the reproductive system. Microbiol. Mol. Biol. Rev. 65, 208-231 (2001).

127. Cheng, C. Y. \& Mruk, D. D. The blood-testis barrier and its implications for male contraception. Pharmacol. Rev. 64, 16-64 (2012).

128. Almeida, Rd. N. et al. The cellular impact of the ZIKA virus on male reproductive tract immunology and physiology. Cells 9, 1006 (2020).

129. Patel, D. P. et al. The impact of SARS-CoV-2 and COVID-19 on male reproduction and men's health. Fertil. Steril. 115, 813-823 (2021).

130. Mruk, D. D. \& Cheng, C. Y. The mammalian bloodtestis barrier: its biology and regulation. Endocr. Rev. 36, 564-591 (2015)

131. Siemann, D. N., Strange, D. P., Maharaj, P. N., Shi, P.-Y. \& Verma, S. Zika virus infects human Sertoli cells and modulates the integrity of the in vitro blood testis barrier model. J. Virol. 91, e00623-00617 (2017).

132. Leda, A. R. et al. Selective disruption of the bloodbrain barrier by Zika virus. Front. Microbiol. 10 , 2158 (2019).

133. Hanchard, J., Capó-Vélez, C. M., Deusch, K., Lidington, D. \& Bolz, S.-S. Stabilizing cellular barriers: raising the shields against COVID-19. Front. Endocrinol. 11, 583006 (2020). 
134. Buzhdygan, T. P et al. The SARS-CoV-2 spike protein alters barrier function in 2D static and 3D microfluidic in-vitro models of the human blood-brain barrier. Neurobiol. Dis. 146, 105131 (2020).

135. Sivabakya, T. K. \& Srinivas, G. Lung barrier function in COVID-19? SN Compr. Clin. Med. 2, 1299-1301 (2020).

136. Zhang, L. et al. SARS-CoV-2 crosses the blood-brain barrier accompanied with basement membrane disruption without tight junctions alteration. Signal. Transduct. Target. Ther. 6, 337 (2021).

137. Lukassen, S. et al. SARS-CoV-2 receptor ACE2 and TMPRSS 2 are primarily expressed in bronchial transient secretory cells. EMBO J. 39, e105114 (2020).

138. Hamming, I. et al. Tissue distribution of ACE2 protein the functional receptor for SARS coronavirus. A first step in understanding SARS pathogenesis. J. Pathol. 203, 631-637 (2004).

139. Xu, H. et al. High expression of ACE2 receptor of 2019-nCoV on the epithelial cells of oral mucosa. Int. J. Oral. Sci. 12, 8 (2020)

140. Bourgonje, A. R. et al. Angiotensin-converting enzyme 2 (ACE2), SARS-CoV-2 and the pathophysiology of coronavirus disease 2019 (COVID-19). J. Pathol. 251, 228-248 (2020).

141. Salamanna, F., Maglio, M., Landini, M. P \& Fini, M Body localization of ACE-2: on the trail of the keyhole of SARS-CoV-2. Front. Med. 7, 594495 (2020).

142. Li, S. et al. SARS-CoV-2 triggers inflammatory responses and cell death through caspase- 8 activation. Signal. Transduct. Target. Ther. 5, 235 (2020).

143. Deinhardt-Emmer, S. et al. SARS-CoV-2 causes severe epithelial inflammation and barrier dysfunction. J. Virol. 95, e00110-e00121 (2021).

144. Gkogkou, E., Barnasas, G., Vougas, K. \& Trougakos, I. P. Expression profiling meta-analysis of ACE2 and TMPRSS2, the putative anti-inflammatory receptor and priming protease of SARS-CoV-2 in human cells, and identification of putative modulators. Redox Biol. 36, 101615 (2020).

145. Pan, F. et al. No evidence of severe acute respiratory syndrome-coronavirus 2 in semen of males recovering from coronavirus disease 2019. Fertil. Steril. 113 1135-1139 (2020)

146. Stanley, K. E., Thomas, E., Leaver, M. \& Wells, D. Coronavirus disease-19 and fertility: viral host entry protein expression in male and female reproductive tissues. Fertil. Steril. 114, 33-43 (2020).

147. Pan, P.-P., Zhan, Q.-T., Le, F., Zheng, Y.-M. \& Jin, F Angiotensin-converting enzymes play a dominant role in fertility. Int. J. Mol. Sci. 14, 21071-21086 (2013).

148. Verma, S., Saksena, S. \& Sadri-Ardekani, H. ACE2 receptor expression in testes: implications in coronavirus disease 2019 pathogenesist. Biol. Reprod. 103, 449-451 (2020).

149. Wang, Z. \& Xu, X. scRNA-seq profiling of human testes reveals the presence of the ACE2 receptor, a target for SARS-CoV-2 infection in spermatogonia, Leydig and Sertoli cells. Cells 9, 920 (2020).

150. Douglas, G. C. et al. The novel angiotensin-converting enzyme (ACE) homolog, ACE2, is selectively expressed by adult Leydig cells of the testis. Endocrinology 145 , 4703-4711 (2004)

151. Navarra, A., Albani, E., Castellano, S., Arruzzolo, L. $\&$ Levi-Setti, P. E. Coronavirus disease-19 infection: implications on male fertility and reproduction. Front. Physiol. 11, 574761 (2020)

152. Fan, C., Lu, W., Li, K., Ding, Y. \& Wang, J. ACE2 expression in kidney and testis may cause kidney and testis infection in COVID-19 patients. Front. Med. 7 563893 (2021).

153. Song, H., Seddighzadeh, B., Cooperberg, M. R. \& Huang, F. W. Expression of ACE2, the SARS-CoV-2 receptor, and TMPRSS2 in prostate epithelial cells. Eur. Urol. 78, 296-298 (2020).

154. Zhou, L. et al. SARS-CoV-2 targets by the pscRNA profiling of ACE2, TMPRSS 2 and furin proteases. iScience 23, 101744 (2020).

155. Lazartigues, E., Qadir, M. M. F. \& Mauvais-Jarvis, F. Endocrine significance of SARS-CoV-2's reliance on ACE2. Endocrinology 161, bqaa108 (2020).

156. Lazartigues, E., Qadir, M. M. F. \& Mauvais-Jarvis, F. Endocrine significance of SARS-CoV-2's reliance on ACE2. Endocrinology 161, bqaa108 (2020).

157. Pal, R. \& Banerjee, M. COVID-19 and the endocrine system: exploring the unexplored. J. Endocrinol. Invest. 43, 1027-1031 (2020)

158. Piticchio, T., Le Moli, R., Tumino, D. \& Frasca, F. Relationship between betacoronaviruses and the endocrine system: a new key to understand the
COVID-19 pandemic - a comprehensive review. J. Endocrinol. Invest. 44, 1553-1570 (2021).

159. Çayan, S., Uğuz, M., Saylam, B. \& Akbay, E. Effect of serum total testosterone and its relationship with other laboratory parameters on the prognosis of coronavirus disease 2019 (COVID-19) in SARS-CoV-2 infected male patients: a cohort study. Aging Male 23 1493-1503 (2020).

160. Ma, L. et al. Evaluation of sex-related hormones and semen characteristics in reproductive-aged male COVID-19 patients. J. Med. Virol. 93, 456-462 (2021).

161. Toufexis, D., Rivarola, M. A., Lara, H. \& Viau, V. Stress and the reproductive axis. J. Neuroendocrinol. 26, 573-586 (2014)

162. Pal, R. COVID-19, hypothalamo-pituitary-adrenal axis and clinical implications. Endocrine 68, 251-252 (2020).

163. Leow, M. K.-S. et al. Hypocortisolism in survivors of severe acute respiratory syndrome (SARS). Clin. Endocrinol. 63, 197-202 (2005).

164. Zhao, J.-M. et al. Clinical pathology and pathogenesis of severe acute respiratory syndrome. Zhonghua Shi Yan He Lin. Chuang Bing. Du. Xue Za Zhi 17, 217-22 (2003).

165. Xu, J. et al. Orchitis: a complication of severe acute respiratory syndrome (SARS) 1. Biol. Reprod. 74, 410-416 (2006)

166. Wang, S., Zhou, X., Zhang, T. \& Wang, Z. The need for urogenital tract monitoring in COVID-19. Nat. Rev. Urol. 17, 314-315 (2020)

167. Cardona Maya, W. D., Du Plessis, S. S. \& Velilla, P. A. SARS-CoV-2 and the testis: similarity with other viruses and routes of infection. Reprod. Biomed. Online 40, 763-764 (2020).

168. La Marca, A. et al. Testicular pain as an unusual presentation of COVID-19: a brief review of SARS CoV-2 and the testis. Reprod. Biomed. Online 41 903-906 (2020).

169. Ediz, C. et al. Is there any association of COVID-19 with testicular pain and epididymo-orchitis? Int. J. Clin. Pract. 75, e13753 (2021).

170. Kim, J., Thomsen, T., Sell, N. \& Goldsmith, A. J. Abdominal and testicular pain: an atypical presentation of COVID-19. Am. J. Emerg. Med. 38, 1542.e1541-1542.e1543 (2020)

171. Bridwell, R. E., Merrill, D. R., Griffith, S. A., Wray, J. \& Oliver, J. J. A coronavirus disease 2019 (COVID-19) patient with bilateral orchitis. Am. J. Emerg. Med. 42 260.e3-260.e5 (2021)

172. Gagliardi, L. et al. Orchiepididymitis in a boy with COVID-19. Pediatr. Infect. Dis. J. 39, e200-e202 (2020).

173. Chen, L. et al. Ultrasound imaging findings of acute testicular infection in patients with coronavirus disease 2019: a single-center-based study in Wuhan, China. J. Ultrasound Med. 40, 1787-1794 (2020).

174. Falahieh, F.M. et al. Effects of moderate COVID-19 infection on semen oxidative status and parameters 14 and 120 days after diagnosis. Reprod. Fertil. Dev. 33, 683-690 (2021)

175. Li, H. et al. Impaired spermatogenesis in COVID-19 patients. EClinicalMedicine 28, 100604 (2020).

176. Salciccia, S. et al. Interplay between male testosterone levels and the risk for subsequent invasive respiratory assistance among COVID-19 patients at hospital admission. Endocrine 70, 206-210 (2020).

177. Rastrelli, G. et al. Low testosterone levels predict clinical adverse outcomes in SARS-CoV-2 pneumonia patients. Andrology 9, 88-98 (2021).

178. Wei, L. et al. Endocrine cells of the adenohypophysis in severe acute respiratory syndrome (SARS). Biochem. Cell Biol. 88, 723-730 (2010).

179. Sharun, K., Tiwari, R. \& Dhama, K. SARS-CoV-2 in semen: potential for sexual transmission in COVID-19. Int. J. Surg. 84, 156-158 (2020)

180. Li, D., Jin, M., Bao, P., Zhao, W. \& Zhang, S. Clinical characteristics and results of semen tests among men with coronavirus disease 2019. JAMA Netw. Open 3 , e208292-e208292 (2020)

181. Mohseni, A. H., Taghinezhad-S, S., Xu, Z. \& Fu, X Body fluids may contribute to human-to-human transmission of severe acute respiratory syndrome coronavirus 2: evidence and practical experience. Chin. Med. 15, 58 (2020).

182. He, W. et al. Impact of SARS-CoV-2 on male reproductive health: a review of the literature on male reproductive involvement in COVID-19. Front. Med. 7, 594364 (2020)

183. He, W. et al. Impact of SARS-CoV-2 on male reproductive health: a review of the literature on male reproductive involvement in COVID-19. Front. Med. 7, 594364 (2020).
184. Atkinson, B. et al. Presence and persistence of zika virus RNA in semen, United Kingdom, 2016. Emerg. Infect. Dis. 23, 611-615 (2017).

185. Li, F. et al. Distinct mechanisms for TMPRSS2 expression explain organ-specific inhibition of SARS-CoV-2 infection by enzalutamide. Nat. Commun 12, 866 (2021)

186. Zupin, L., Pascolo, L., Zito, G., Ricci, G. \& Crovella, S. SARS-CoV-2 and the next generations: which impact on reproductive tissues? J. Assist. Reprod. Genet. 37 2399-2403 (2020).

187. La Marca, A., Niederberger, C., Pellicer, A. \& Nelson, S. M. COVID-19: lessons from the Italian reproductive medical experience. Fertil. Steril. 113, 920-922 (2020).

188. Donoghue, $\mathrm{M}$. et al. A novel angiotensin-converting enzyme-related carboxypeptidase (ACE2) converts angiotensin I to angiotensin 1-9. Circ. Res. 87, e1-e9 (2000).

189. Vaarala, M. H., Porvari, K. S., Kellokumpu, S. Kyllönen, A. P. \& Vihko, P. T. Expression of transmembrane serine protease TMPRSS2 in mouse and human tissues. J. Pathol. 193, 134-140 (2001).

190. Pinto, B. G. G. et al. ACE2 expression is increased in the lungs of patients with comorbidities associated with severe COVID-19. J. Infect. Dis. 222, 556-563 (2020).

191. Erbay, G. et al. Short-term effects of COVID-19 on semen parameters: a multicenter study of 69 cases. Andrology 9, 1060-1065 (2021).

192. Aquila, I. et al. SARS-CoV-2 pandemic: review of the literature and proposal for safe autopsy practice. Arch. Pathol. Lab. Med. 73, 101999 (2020).

193. Bian, X.-W. \& Team, T. C.-P. Autopsy of COVID-19 patients in China. Natl Sci. Rev. 7, 1414-1418 (2020).

194. Massarotti, C et al. SARS-CoV-2 in the semen: where does it come from? Andrology 9, 39-41 (2021).

195. Yang, M. et al. Pathological findings in the testes of COVID-19 patients: clinical implications. Eur. Urol. Focus. 6,11241129(2020)

196. Duarte-Neto, A. N. et al. Testicular pathology in fatal COVID-19: a descriptive autopsy study. Andrology https://doi.org/10.1111/andr.13073 (2021).

197. Nie, X. et al. Multi-organ proteomic landscape of COVID-19 autopsies. Cell 184, 775-791.e714 (2021).

198. Moghimi, N. et al. COVID-19 disrupts spermatogenesis through the oxidative stress pathway following induction of apoptosis. Apoptosis 26, 415-430 (2021).

199. Peirouvi, T. et al. COVID-19 disrupts the blood-testis barrier through the induction of inflammatory cytokines and disruption of junctional proteins. Inflamm. Res. 26, 1-11 (2021).

200. Ma, X. et al. Pathological and molecular examinations of postmortem testis biopsies reveal SARS-CoV-2 infection in the testis and spermatogenesis damage in COVID-19 patients. Cell Mol. Immunol. 18, 487-489 (2021).

201. Achua, J. K. et al. Histopathology and ultrastructural findings of fatal COVID-19 infections on testis. World J. Mens Health 39, 65-74 (2021).

202. Maiese, A. et al. Autopsy findings in COVID-19-related deaths: a literature review. Forensic Sci. Med. Pathol. 17, 279-296 (2020).

203. Ruiz, S. I., Zumbrun, E. E. \& Nalca, A. in Animal Models for the Study of Human Disease 2nd edn (ed. Conn, P. M.) 853901 (Academic Press, 2017).

204. González, R. \& Dobrinski, I. Beyond the mouse monopoly: studying the male germ line in domestic animal models. ILAR J. 56, 83-98 (2015).

205. Roberts, A. et al. Animal models and vaccines for SARS-CoV infection. Virus Res. 133, 20-32 (2008).

206. Agrawal, A. S. et al. Generation of a transgenic mouse model of middle east respiratory syndrome coronavirus infection and disease. J. Virol. 89, 3659 (2015).

207. Tao, X. et al. Characterization and demonstration of the value of a lethal mouse model of middle east respiratory syndrome coronavirus infection and disease. J. Virol. 90, 57 (2016)

208. Bao, L. et al. The pathogenicity of SARS-CoV- 2 in hACE2 transgenic mice. Nature $583,830-833$ (2020).

209. Martina, B. E. E. et al. Virology: SARS virus infection of cats and ferrets. Nature 425, 915-915 (2003).

210. Sia, S. F. et al. Pathogenesis and transmission of SARS-CoV-2 in golden hamsters. Nature 583 . 834-838 (2020).

211. Campos, R. K. et al. SARS-CoV-2 infects hamster testes. Microorganisms 9, 1318 (2021). 
212. Estes, J. D., Wong, S. W. \& Brenchley, J. M Nonhuman primate models of human viral infections. Nat. Rev. Immunol. 18, 390-404 (2018).

213. Osuna, C. E. \& Whitney, J. B. Nonhuman primate models of Zika virus infection, immunity, and therapeutic development. J. Infect. Dis. 216, S928-S934 (2017)

214. Haagmans, B. L. \& Osterhaus, A. D. M. E. Nonhuman primate models for SARS. PLoS Med. 3, e194 (2006).

215. de Wit, E. et al. Middle East respiratory syndrome coronavirus (MERS-CoV) causes transient lower respiratory tract infection in rhesus macaques. Proc. Natl Acad. Sci. USA 110, 16598 (2013).

216. Chao Shan, Y.-F. Y. \& Yang, X.-L. et al. Infection with novel coronavirus (SARS-CoV-2) causes pneumonia in the rhesus macaques. Cell Res. 30, 670-677 (2020).

217. Totura, A. et al. Small particle aerosol exposure of African Green monkeys to MERS-CoV as a model for highly pathogenic coronavirus infection. Emerg. Infect. Dis. J. 26, 2835-2843 (2020).

218. Neff, E. African green monkey Zika models. Lab. Anim 49, 224-224 (2020).

219. Laksono, B. M. et al. Studies into the mechanism of measles-associated immune suppression during a measles outbreak in the Netherlands. Nat. Commun 9, 4944 (2018).

220. Alves-Lopes, J. P., Söder, O. \& Stukenborg, J. B. Testicular organoid generation by a novel in vitro three-layer gradient system. Biomaterials 130, 76-89 (2017).

221. Yin, L. et al. High-content image-based single-cell phenotypic analysis for the testicular toxicity prediction induced by bisphenol $A$ and its analogs bisphenol S, bisphenol AF, and tetrabromobisphenol A in a three-dimensional testicular cell co-culture model. Toxicol. Sci. 173, 313-335 (2020)
222. Sakib, S., Voigt, A., Goldsmith, T. \& Dobrinski, I. Three-dimensional testicular organoids as nove in vitro models of testicular biology and toxicology. Environ. Epigenet 5, dvz011 (2019).

223. Fatehullah, A., Tan, S. H. \& Barker, N. Organoids as an in vitro model of human development and disease. Nat Cell Biol 18, 246-254 (2016).

224. Chen, K. G., Park, K. \& Spence, J. R. Studying SARS-CoV-2 infectivity and therapeutic responses with complex organoids. Nat. Cell Biol. 23, 822-833 (2021).

225. Baert, Y. et al. Primary human testicular cells selforganize into organoids with testicular properties. Stem Cell Rep. 8, 30-38 (2017).

226. Strange, D. P. et al. Human testicular organoid system as a novel tool to study Zika virus pathogenesis Emerg. Microbes Infect. 7, 82-82 (2018).

227. Zhang, B.-Z. et al. SARS-CoV-2 infects human neural progenitor cells and brain organoids. Cell Res. 30 928-931 (2020).

228. Matusali, G. et al. Zika virus infects human testicular tissue and germ cells. J. Clin. Invest. 128, 4697-4710 (2018).

229. Chu, H. et al. Comparative replication and immune activation profiles of SARS-CoV-2 and SARS-CoV in human lungs: an ex vivo study with implications for the pathogenesis of COVID-19. Clin. Infect. Dis. 71, 1400-1409 (2020).

230. Yuen, C.-K. et al. Suppression of SARS-CoV-2 infection in ex-vivo human lung tissues by targeting class III phosphoinositide 3-kinase. J. Med. Virol. 93 , 2076-2083 (2021).

231. Easley, C. A. T. et al. Assessing reproductive toxicity of two environmental toxicants with a novel in vitro human spermatogenic model. Stem Cell Res. 14, 347-355 (2015)

232. Greeson, K. W. et al. Detrimental effects of flame retardant, PBB153, exposure on sperm and future generations. Sci. Rep. 10, 8567 (2020).
233. Easley, C. A. T. et al. Direct differentiation of human pluripotent stem cells into haploid spermatogenic cells. Cell Rep. 2, 440-446 (2012).

234. Steves, A. N. et al. Per- and polyfluoroalkyl substances impact human spermatogenesis in a stem-cell-derived model. Syst. Biol. Reprod. Med. 64, 225-239 (2018).

235. Henrich, S. et al. The crystal structure of the proprotein processing proteinase furin explains its stringent specificity. Nat. Struct. Mol. Biol. 10, 520-526 (2003)

236. Wrapp, D. et al. Cryo-EM structure of the 2019-nCoV spike in the prefusion conformation. Science 367, 1260 (2020).

237. Kim, Y. et al. Crystal structure of Nsp15 endoribonuclease NendoU from SARS-CoV-2. Protein Sci. 29, 1596-1605 (2020).

238. Meng, T. et al. The insert sequence in SARS-CoV-2 enhances spike protein cleavage by TMPRSS. Preprint at bioRxiv https://doi.org/10.1101/ 2020.02.08.926006 (2020).

\section{Author contributions}

R.C.E. researched data for the article and wrote the manuscript. Both authors contributed substantially to discussion of the content and reviewed and/or edited the manuscript before submission

Competing interests

The authors declare no competing interests.

\section{Peer review information}

Nature Reviews Urology thanks Sandro La Vignera, Daishu Han, Nathalie Dejucq-Rainsford and Louis Bujan for their contribution to the peer review of this work.

\section{Publisher's note}

Springer Nature remains neutral with regard to jurisdictional claims in published maps and institutional affiliations.

(C) Springer Nature Limited 2021 